$\varepsilon r$

دور الجمعيات الأهلية في تنمية المشروعات الصغيرة ومتناهية الصغر بريف محافظة الفيوم

The role of NGOs in the development of micro and small enterprises in rural areas in Fayoum governorate

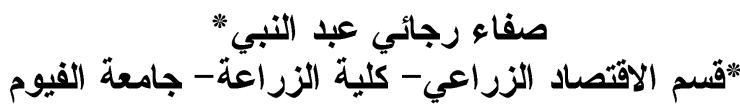

استهدفت هذه الدراسة بصفة أساسية التعرف على دور الجمعيات الأهلية في تنمية

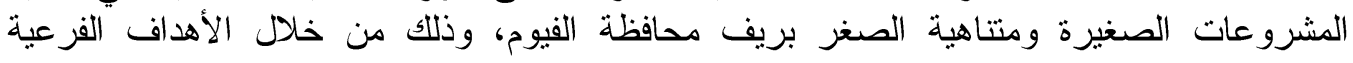

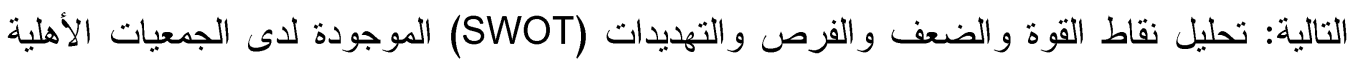

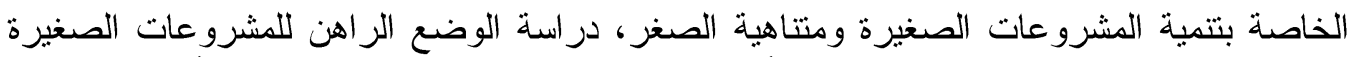

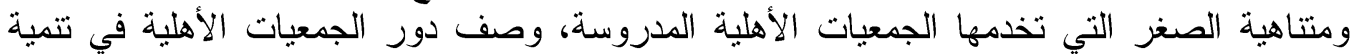

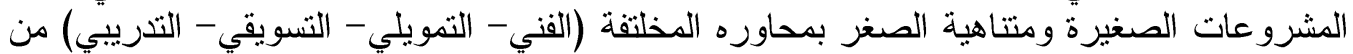

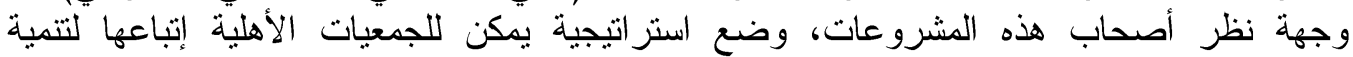

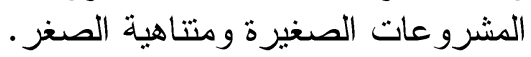

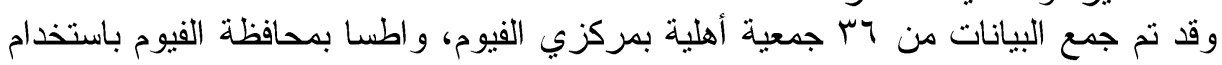

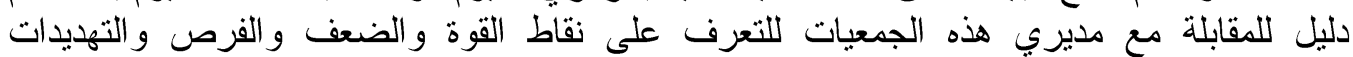

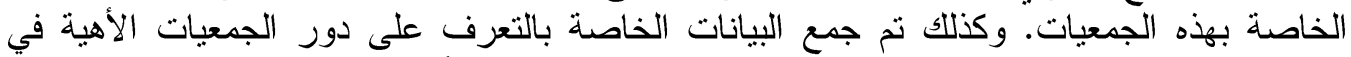

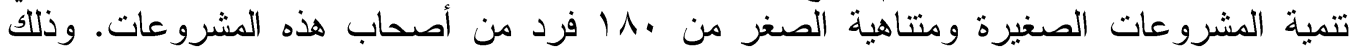

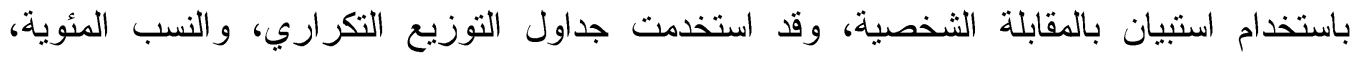

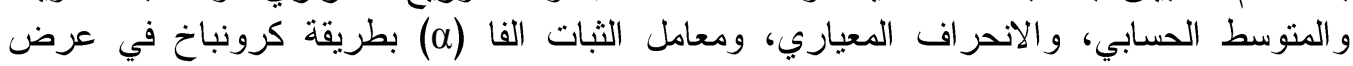
ووصف بيانات الدر اسة.

وقد أظهرت أهم نتائج التحليل الرباعي (SWOT) أن أهم نقاط القوة التي تتمتع بها

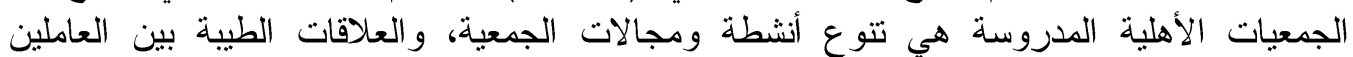

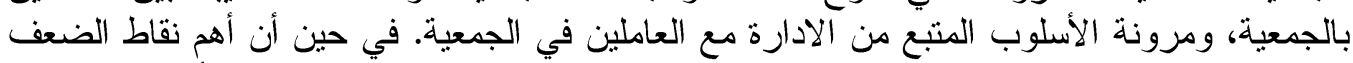

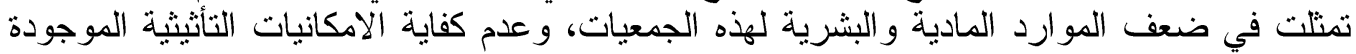

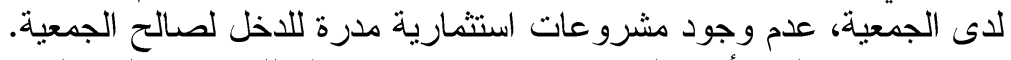

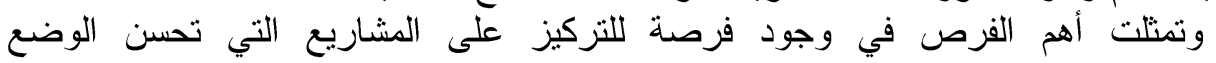

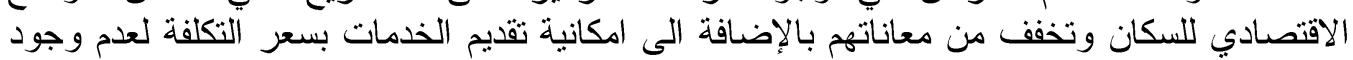

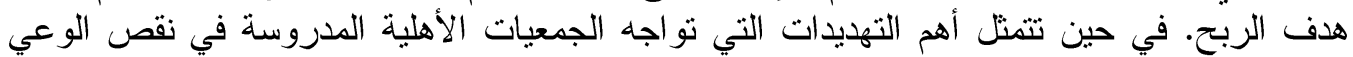

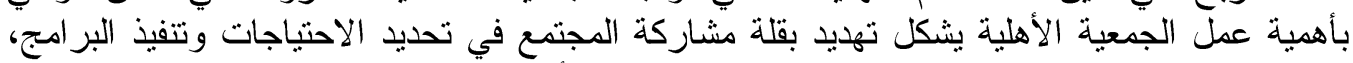

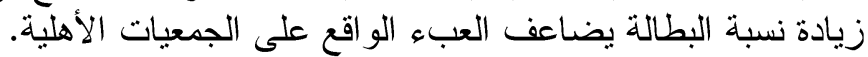

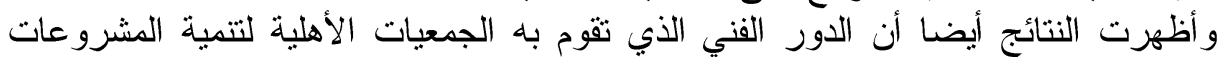

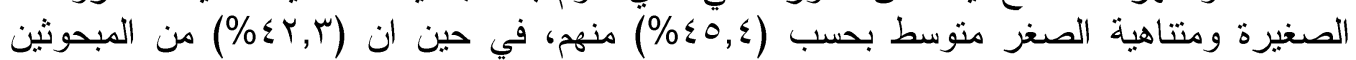

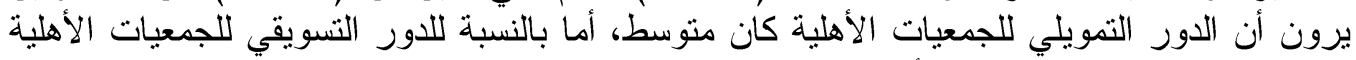

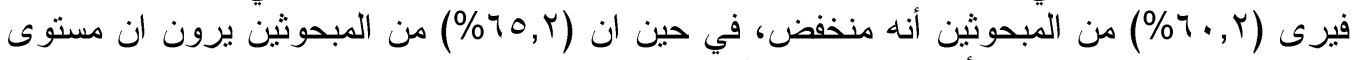

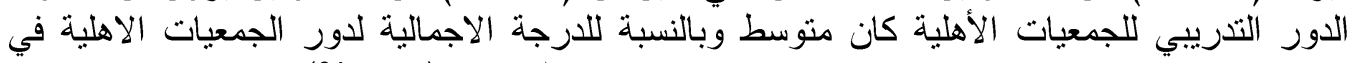

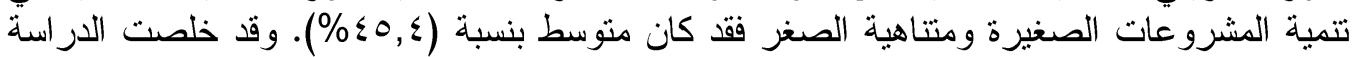

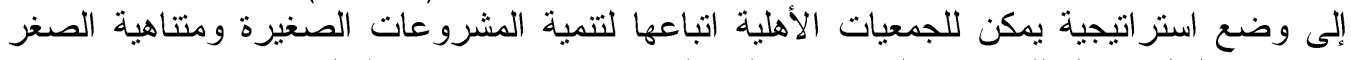
بإعتبار ها الحل الامثل للنهوض بكن بالمجتمعات الريفية وتحسين مستوى معيشة الريفيين.

Fayoum J. Agric. Res. \& Dev., Vol. 33, No.2, July, 2019 
تضمنت وثثقة الأهداف الإنمائية للألفية الثالثة، و التي وقعت عليها دول التيات العالم، ومنها

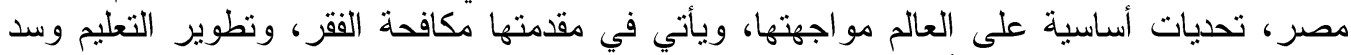

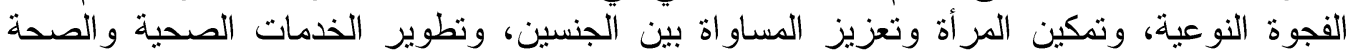

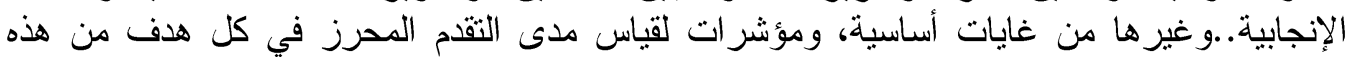

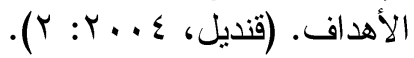

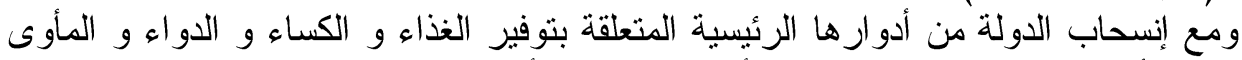

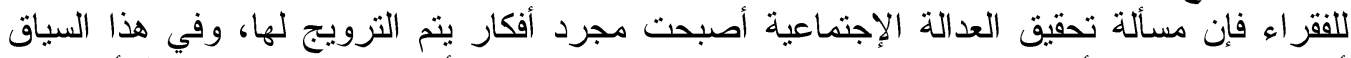

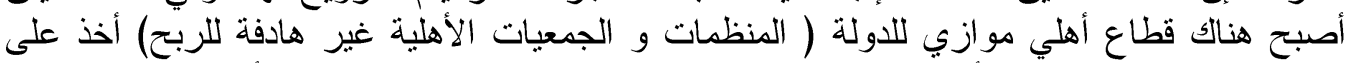

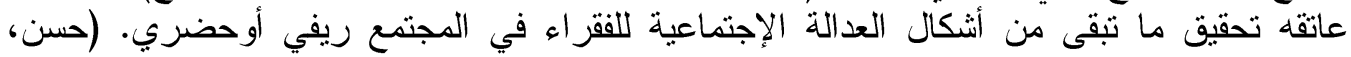

( $r: r \cdot 10$

وتقوم المنظمات غير الحكومية بدور هام وفعال في إثباع الاحتباجات الانسانية

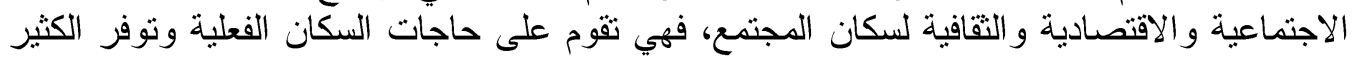

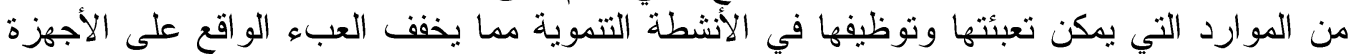

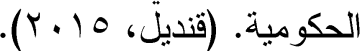

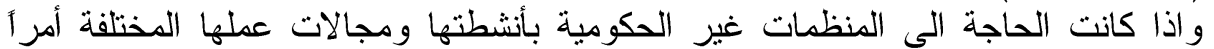

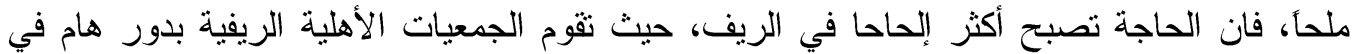

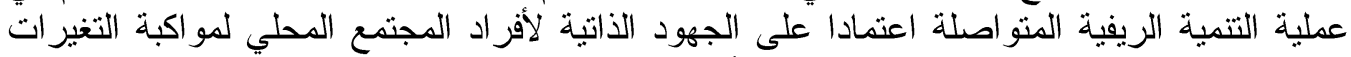

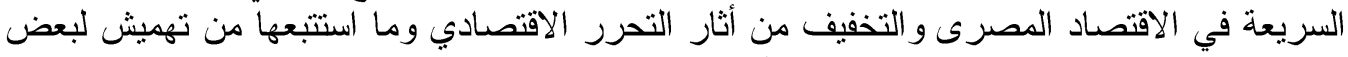

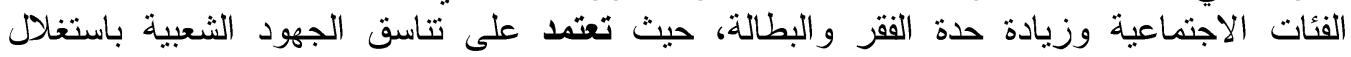

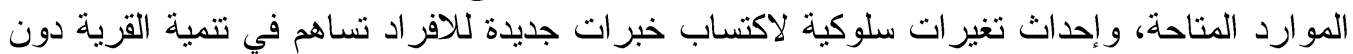

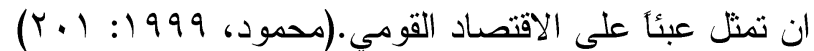

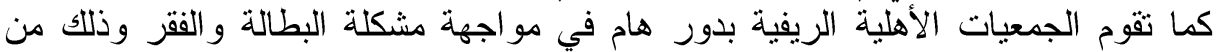

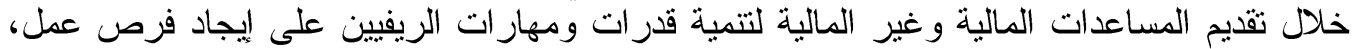

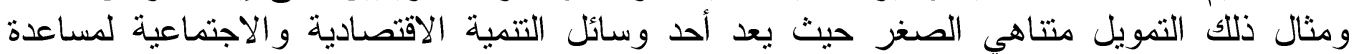

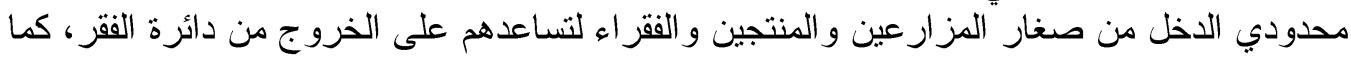

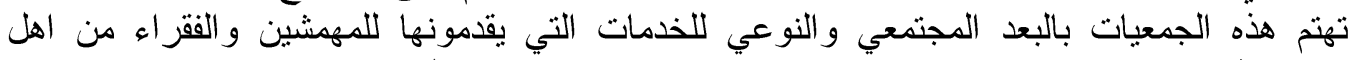

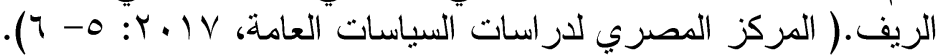

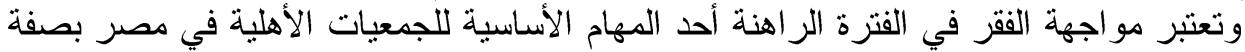

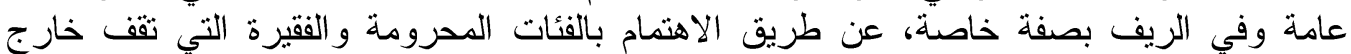

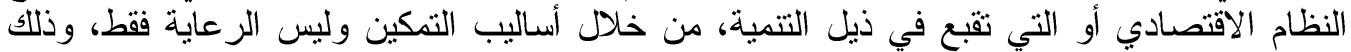

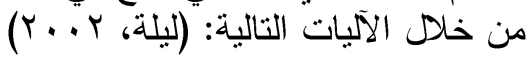

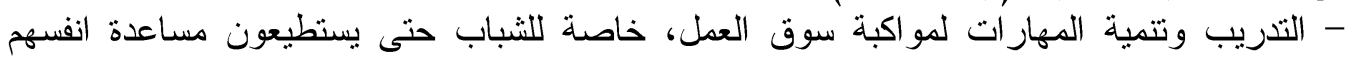
و ايجاد فرص عمل للتقليل من البطالة. - تشجيع العمل المنتج و الصناعل من البطات الصغيرة التي تدر دخلا، أي الاخذ بسياسة الاعتماد على الذات و المشاركة الايجابية. - تفعيل القروض القصيرة و الطويلة الأجل، حيث تقدم جمعيات التتمية قروضا بنسبة فائدة بسيطة جداً

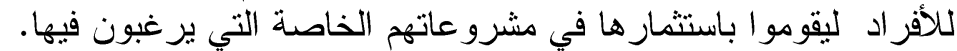

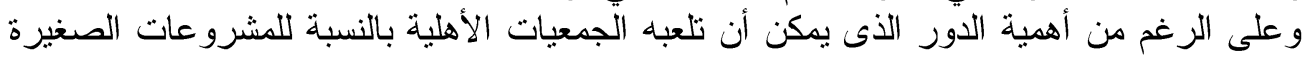

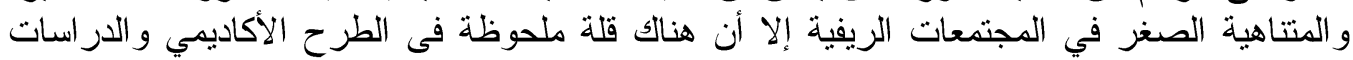

Fayoum J. Agric. Res. \& Dev., Vol. 33, No.2, July, 2019 
Stephenson, Lev and ) الإمبريقية التى تتتاول هذه القضية وخاصة فى سياق الدول النامية

.(Brewer 2007

فغالباً ما يتم التركيز على الدور الذى تمارسه الجمعيات الأهلية من حيث تقديم خدمات الأتيات

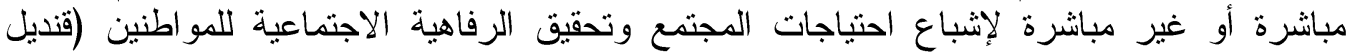

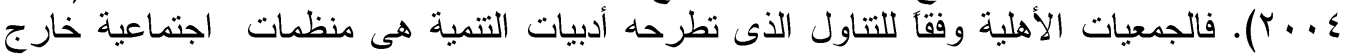

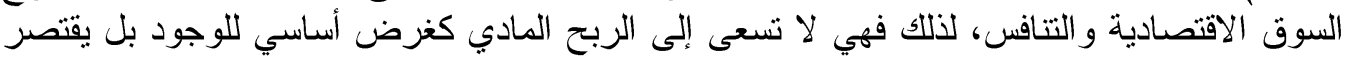

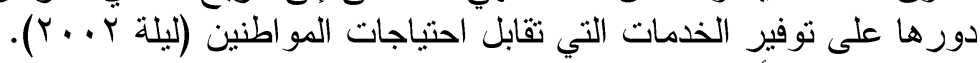

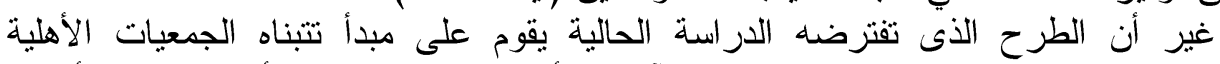

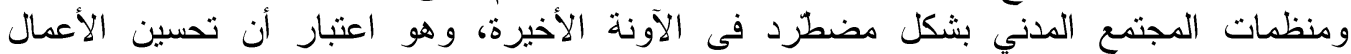

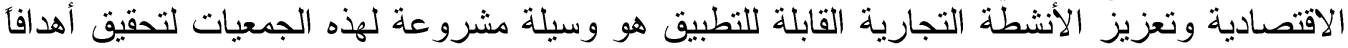

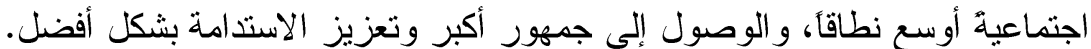

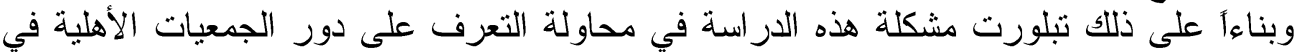

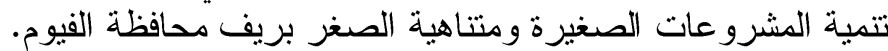

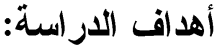

استهدفت هذه الدراسة بصفة أساسية التعرف على دور الجمعيات الأهلية في تتمية

المشروعات الصغيرة ومتتاهية الصغر بريف محافظة الفيوم، وذلك من خلال الأهداف الآلفرعية

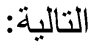

ا- تحليل نقاط القوة و الضعف و الفرص والتهديدات (SWOT) الموجودة لدى الجمعيات الأهلية

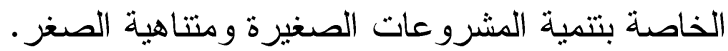

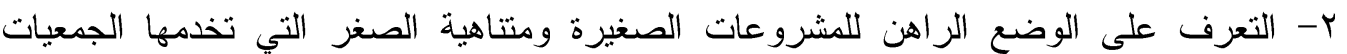
الأهلية المدروسة.

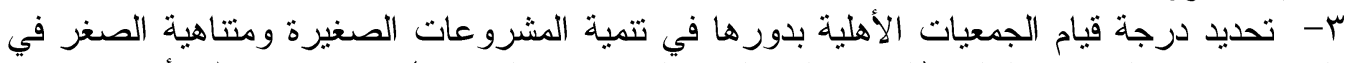
كل محور من المحاور التالية (الفني- التمويلي- آلتسويقي- التندريبي) من وجهة التية نظر أصحاب هذه

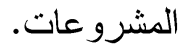

ع - وضع استر اتيجية يمكن للجمعيات الأهلية إتباعها لتتمية المشروعات الصغيرة ومتتاهية الصغر.

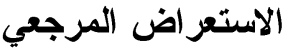

وفقاً لوثائق الأمم المتحدة الصادرة في عام \99 1، تمثل المنظمات غير الحكومية كياناً غير

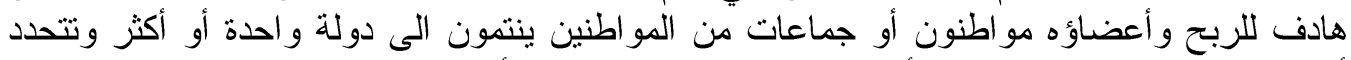

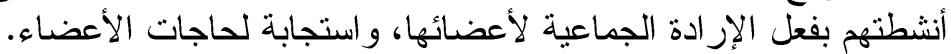

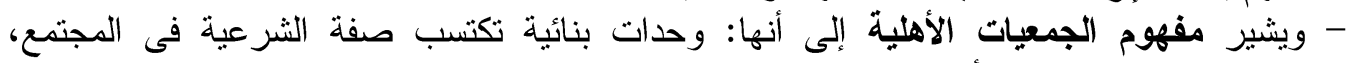

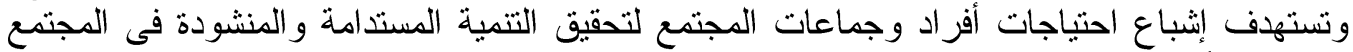

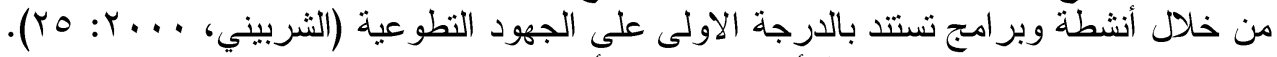

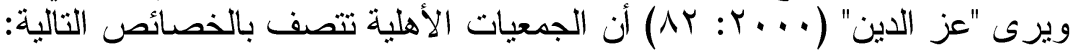

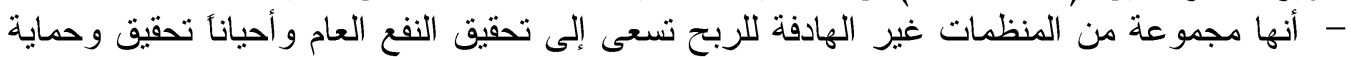
مصالح أعضائها.

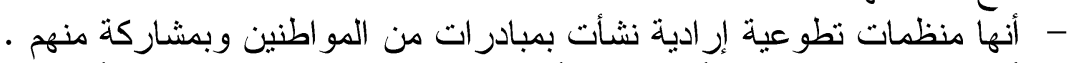

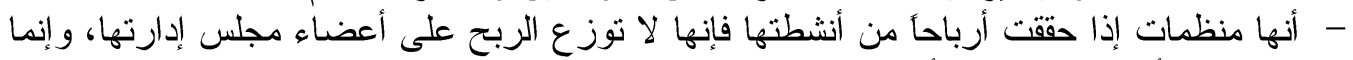

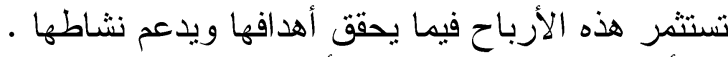

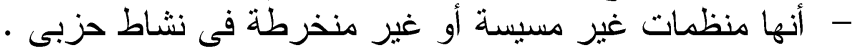

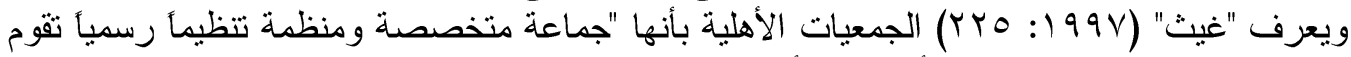

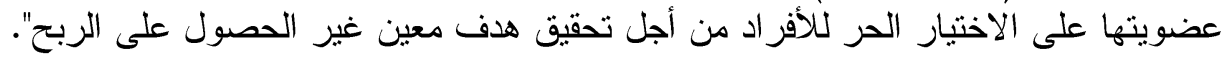

Fayoum J. Agric. Res. \& Dev., Vol. 33, No.2, July, 2019 


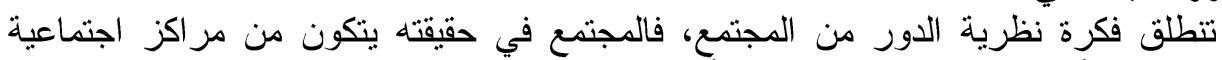

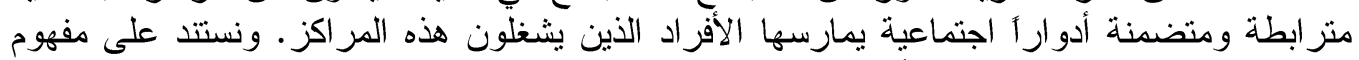

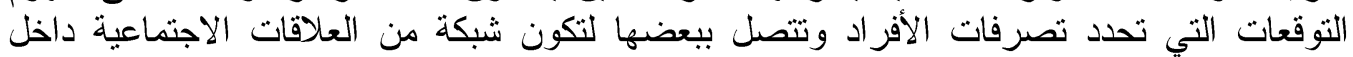

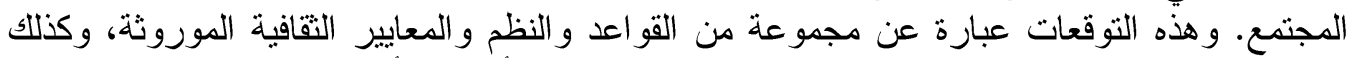

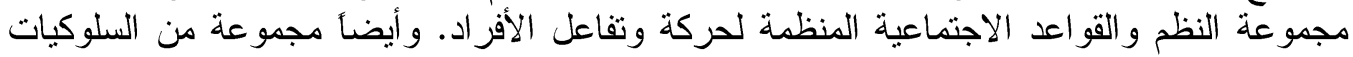

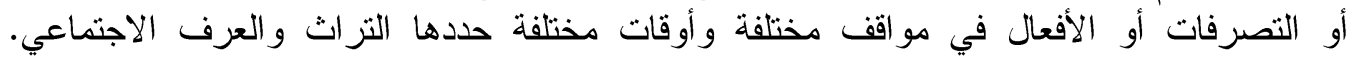

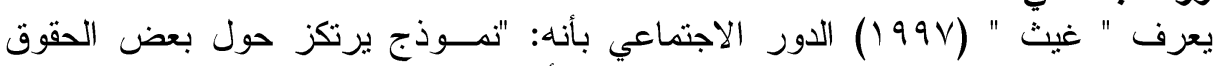

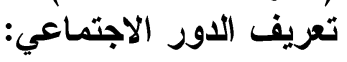

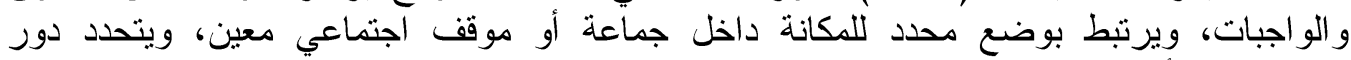

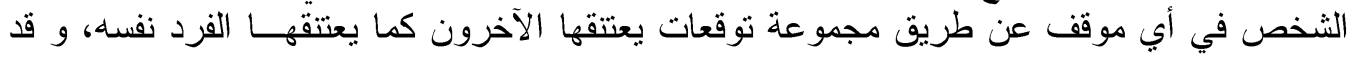

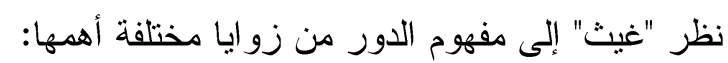

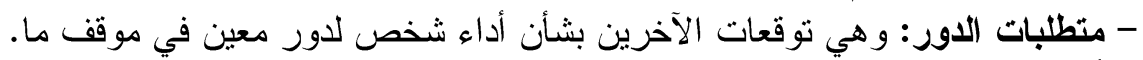

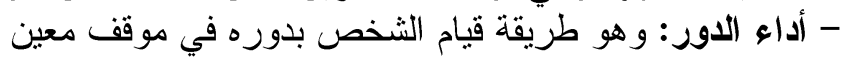

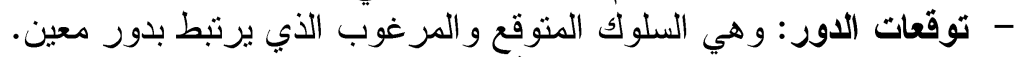

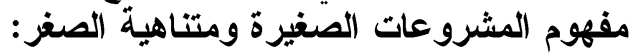

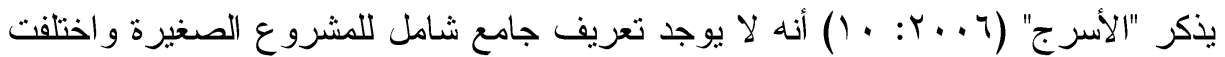

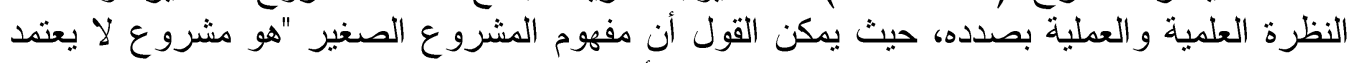

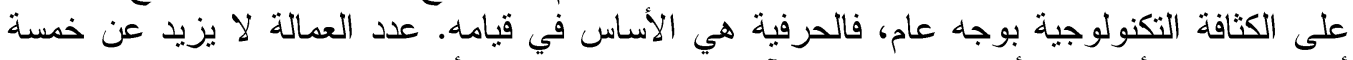

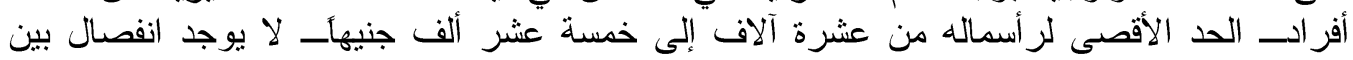

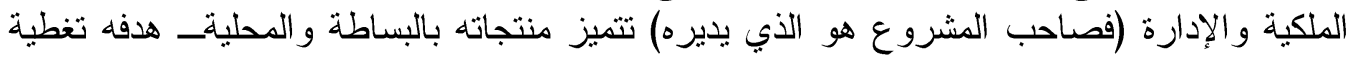

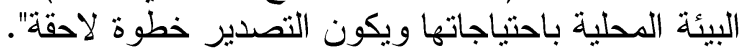

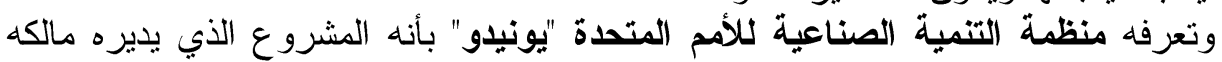

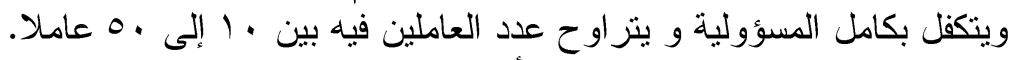

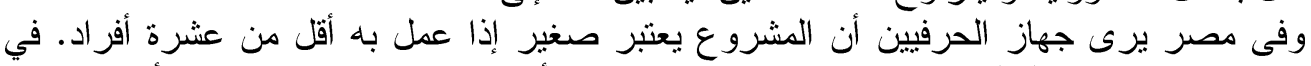

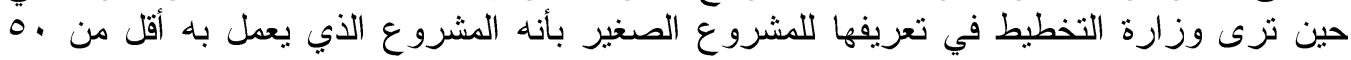

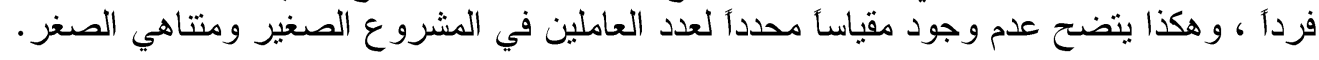

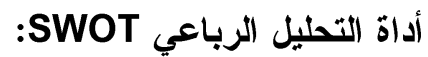

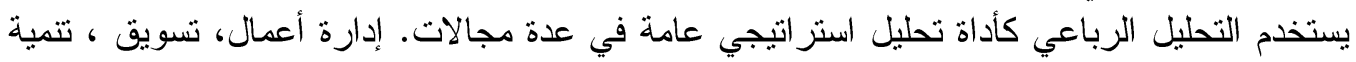

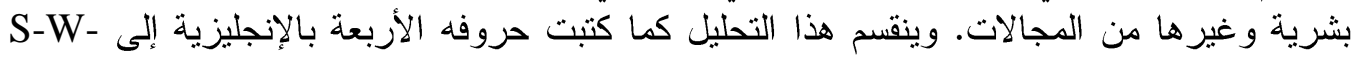

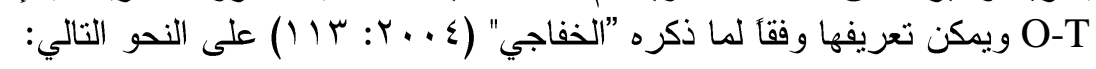

- عناصر القوة

- نقاط الضعف Weaknesses -

Opportunities الفرص -

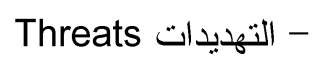
ويلاحظ أنه عند اجراء التحليل الرباعي لأي منظمة فإن:

Fayoum J. Agric. Res. \& Dev., Vol. 33, No.2, July, 2019 
$\varepsilon \uparrow$

- عناصر القوة و نقاط الضعف يخصان الحالة الداخلية للمنظمة، ماهية عناصر القوة الداخلية التي

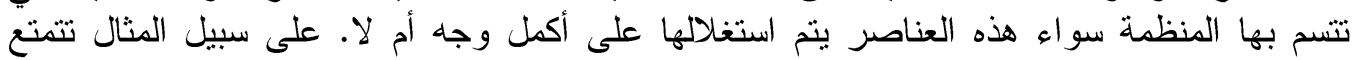

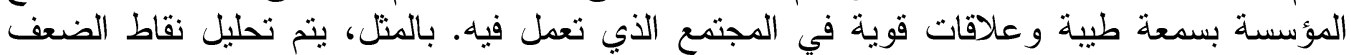

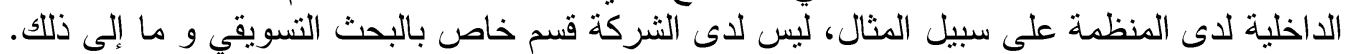

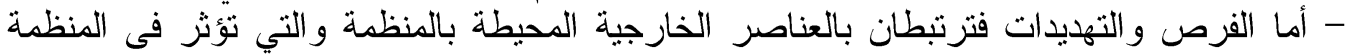

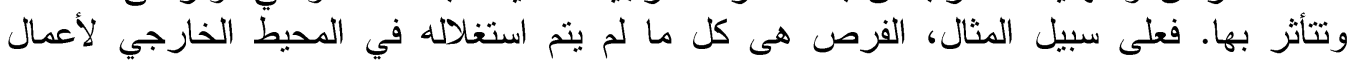

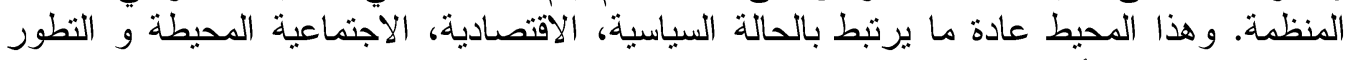

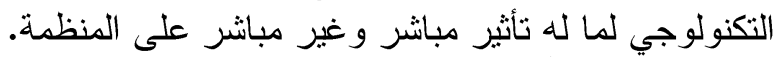
الادر اسات السابقة

تم استعر اض مجموعة من الدراسات السابقة وثيقة الصلة بموضوع الدر اسة و التي اختلفت

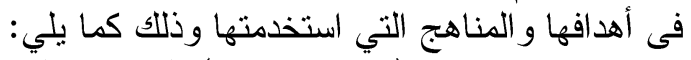

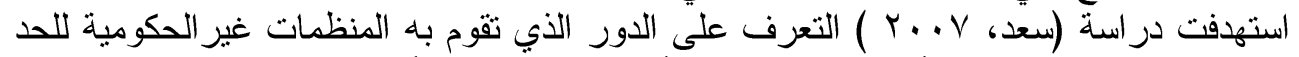

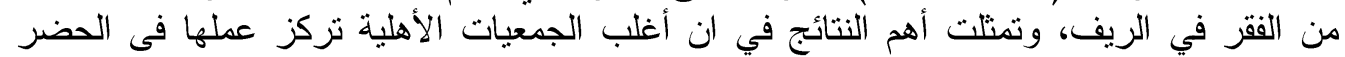

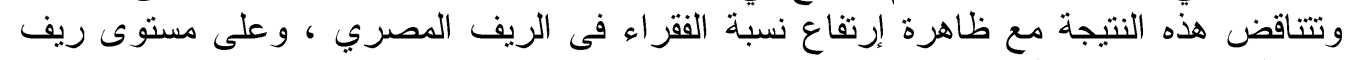

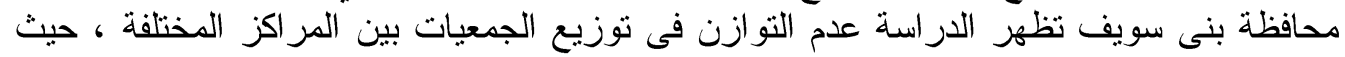

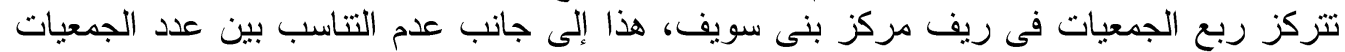

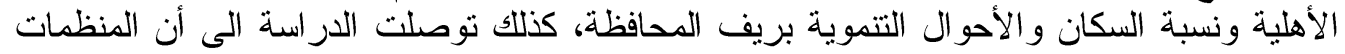

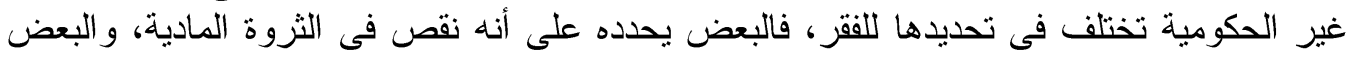

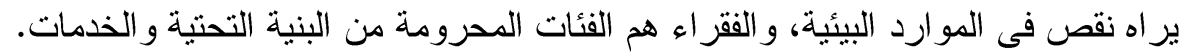

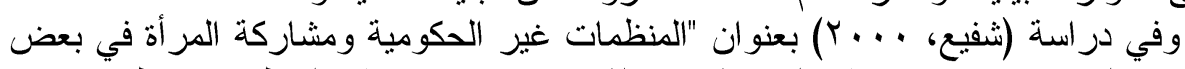

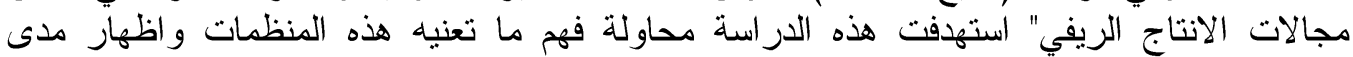
التباين بينها وبين غيرها من المؤسسات الاخرى التي تقوم بعمليات تنموية باعتبارها غير التير حكومية وغير ربحية وفحص البعد التتموي لهذه المونين المنظمات.

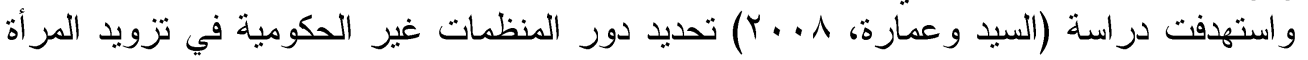

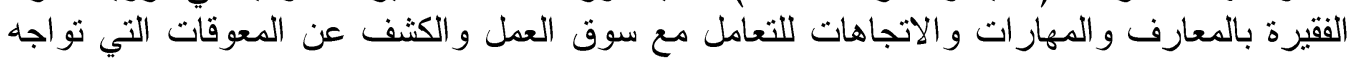

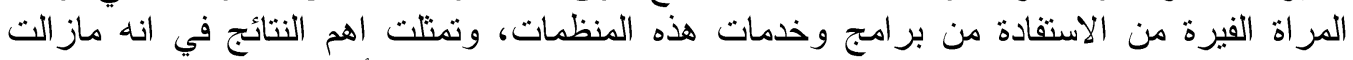

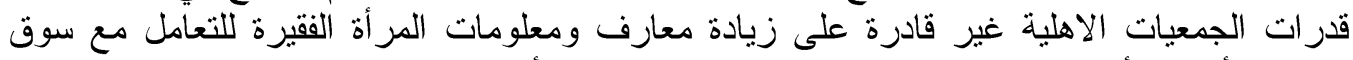

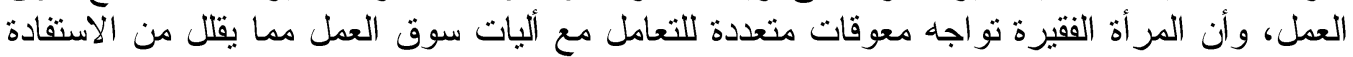
من بر امج وخدمات الجمعيات الأهلية.

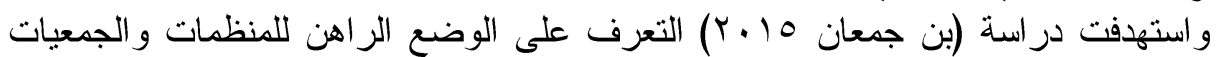

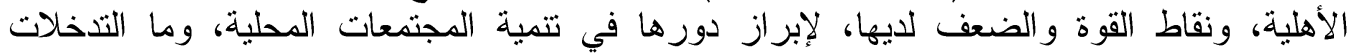

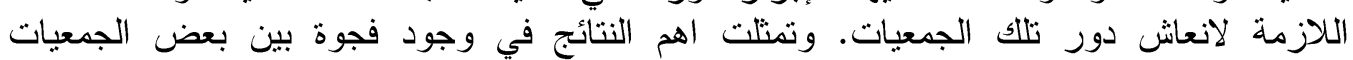

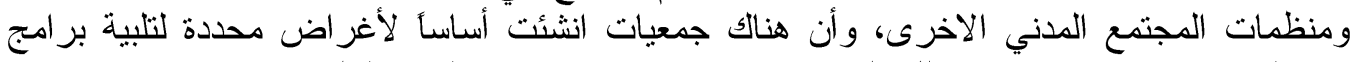

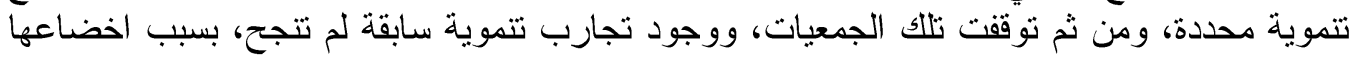

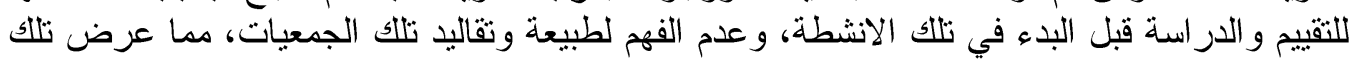

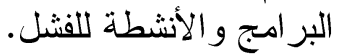

وقد استهدفت دراسة (هريدي، 10 بالج) تحديد دور الجمعيات الأهلية في تحقيق الحماية

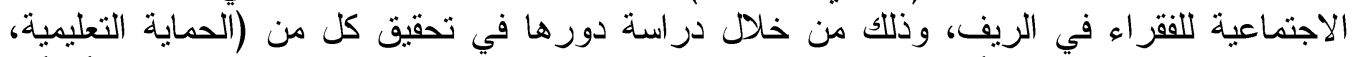

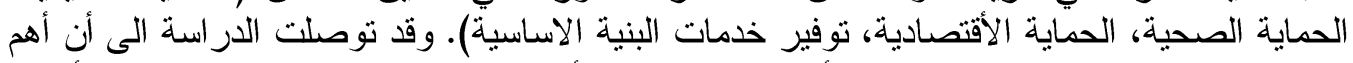

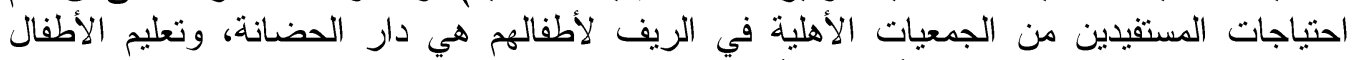

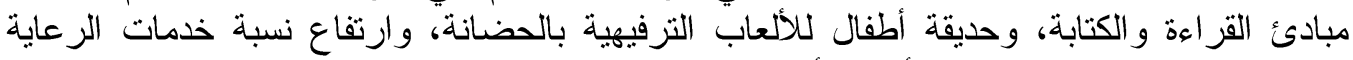

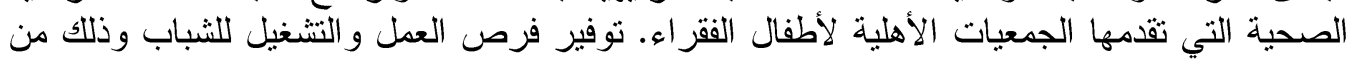

Fayoum J. Agric. Res. \& Dev., Vol. 33, No.2, July, 2019 
$\varepsilon V$

خلال عمل حملات توعية للثاب بأهمية العمل الحر، وتقديم القروض لعمل مشروعاتهم، ودعم

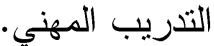
الأسلوب البمثي البمي

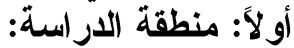

تم إجر اء الدراسة الحالية بمحافظة الفيوم، والتي تقع في الجنوب الغربي من محافظة

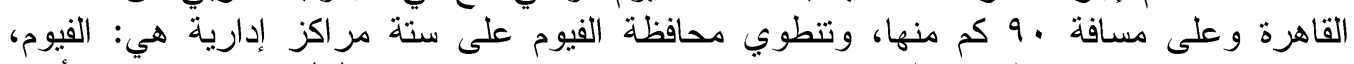

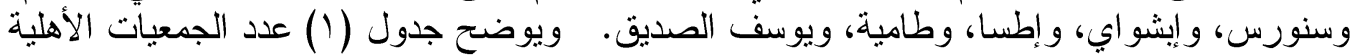

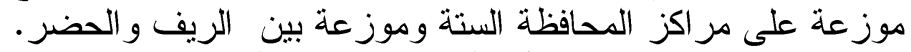
جدول (1) عدد الجمعيات الأهلية بمر اكز محافظة القيوم

\begin{tabular}{|c|c|c|}
\hline ريف & حضر & المركز \\
\hline YII & $\sum \wedge 0$ & الفيوم \\
\hline $10 \leqslant$ & or & سنورس \\
\hline 149 & $r$. & ابشو اي \\
\hline 187 & 11 & اطسا \\
\hline $1 \pi \xi$ & $\varepsilon \varepsilon$ & طامية \\
\hline $10 r$ & 11 & يوسف الصديق \\
\hline 907 & ודו & الاجمالي \\
\hline
\end{tabular}

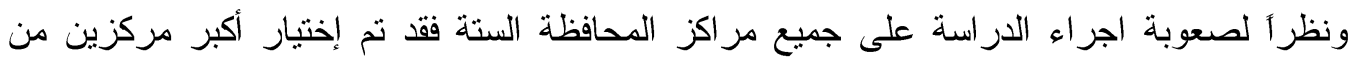

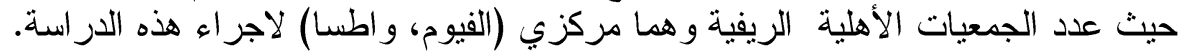

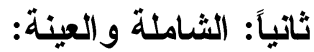

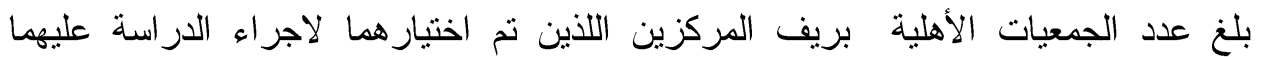

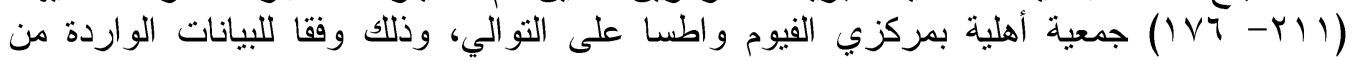

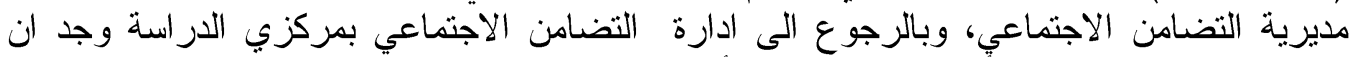

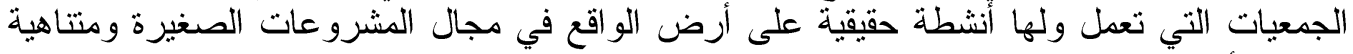

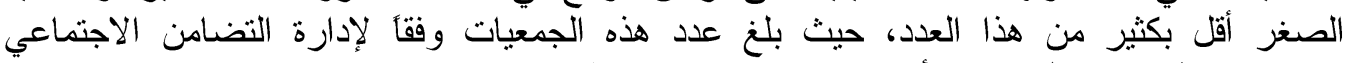

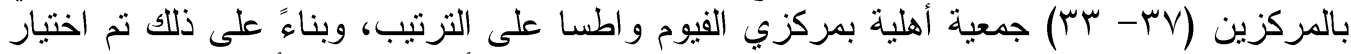

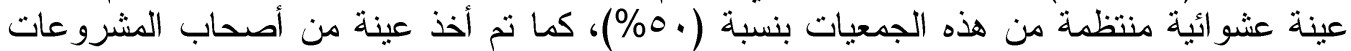

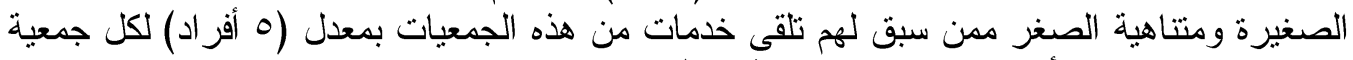

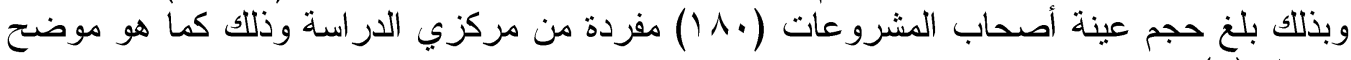

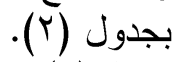
جذول (Y) حجم الثشاملة والعينة من الجمعيات الأهلية الريفية واصحاب المثروعات بمركزي الاراسة

\begin{tabular}{|c|c|c|c|}
\hline عينة اصحاب & 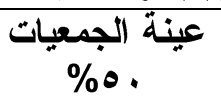 & الشاملة & المركز \\
\hline 90 & 19 & rV & الفيوم \\
\hline 10 & IV & r & اطسا \\
\hline $1 \wedge$. & Ty & $V$. & الاجمال \\
\hline
\end{tabular}

Fayoum J. Agric. Res. \& Dev., Vol. 33, No.2, July, 2019 
لتحقيق اهداف الدراسة تم الاعتماد التان على أكثر من طريقة لجمع البيانات وذلك على النحو التالي:

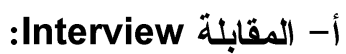

تم تصميم دليل للمقابلة المقننة وتطبيقه على من القائمين علي إدارة الجمعيات الأهلية

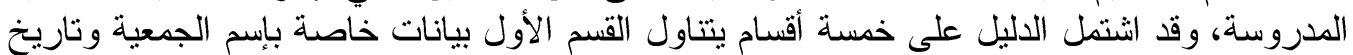

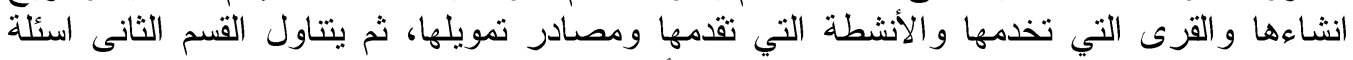

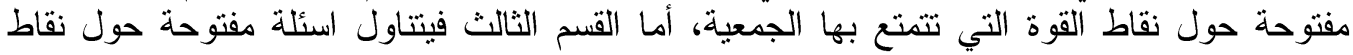

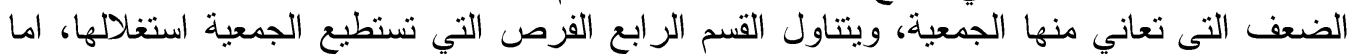

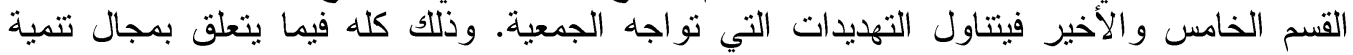
المشروعات الصغيرة ومتتاهية الصغر ـ وقد تم تفريغ البيانات التي تم الحصول عليها من دليل المقابلة وتحليلها و استخر اج النتائج الخاصة بال (SWAT) للجمعيات الأهلية المدروسة.

بuestionnaire الاستبيان

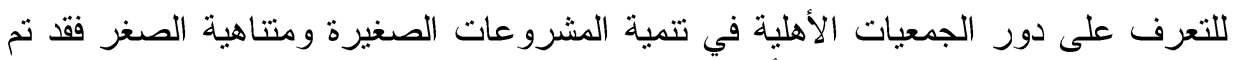

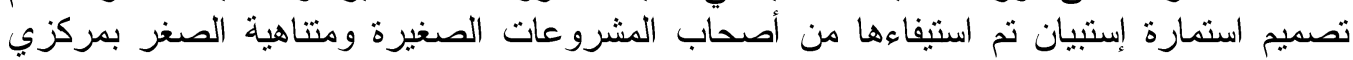

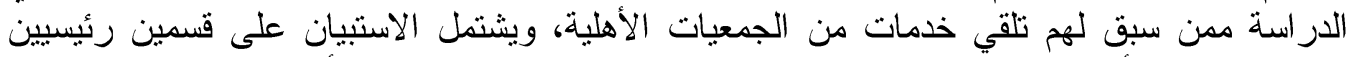

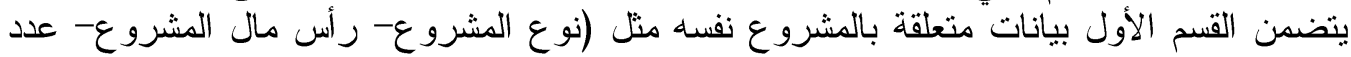

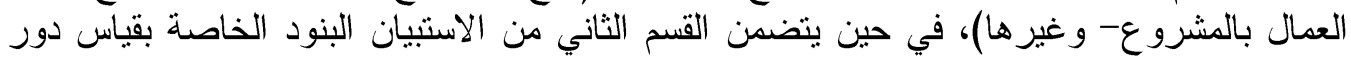

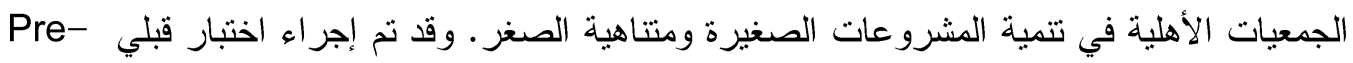
test

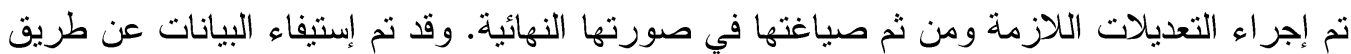

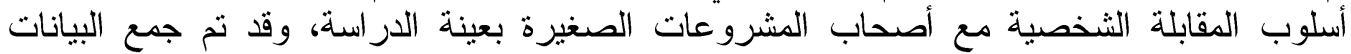

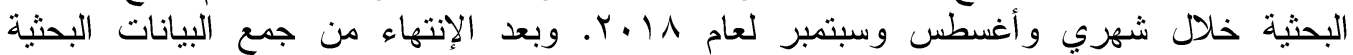

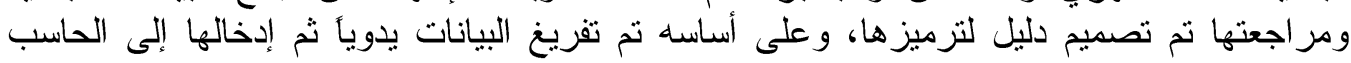

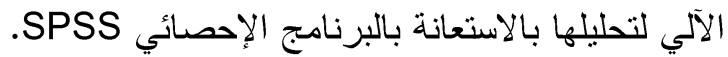

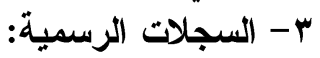

حيث تم الحصول على البيانات الثانوية من السجلات و المنشورات الرسمية الموجودة بمركز

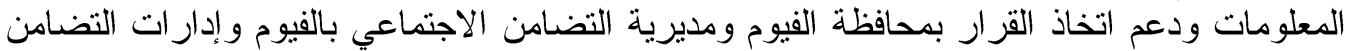

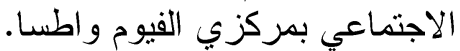
رابعاً: أدوات التحليل الإحصائي: تم تحليل البيانات بالاستعانة بعدد من أساليب التحليل الإنيل الإحصائي التي تتفق وطبيعة الأهداف

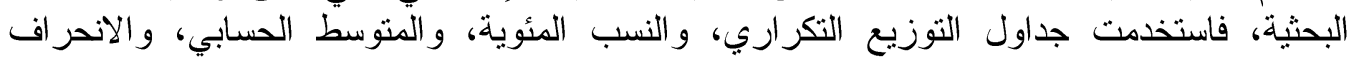

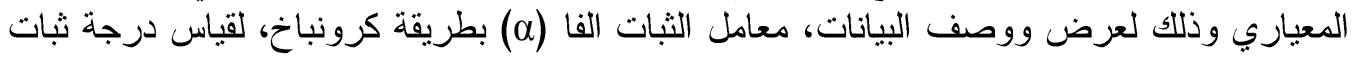
مقياس دور الجمعيات الاهلية. خامساً: المتفيرات البحثية وطرق الأية قياسها:

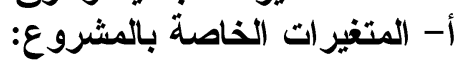

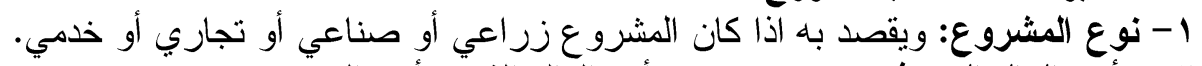

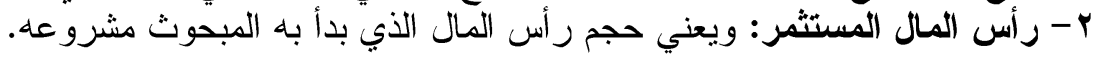

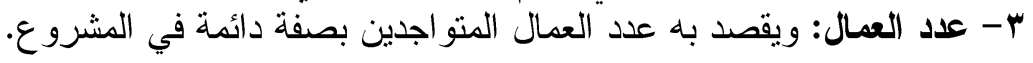

Fayoum J. Agric. Res. \& Dev., Vol. 33, No.2, July, 2019 
$\leqslant 9$

ع - توزيع منتجات المشروع: ويقصد بها اذا كان توزيع المنتجات يتم داخل المحافظة أو بين

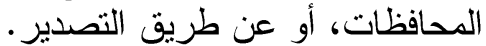
ه- المستوى التكنولوجي المستخلم: ويعني هل يوجد ألات حديثة أم يتم استخدام وسائل بدائية في الانتاج. צ- الوضع القانوني للمشروع: ويعني هل المشروع مرخص ام غير مرخص.

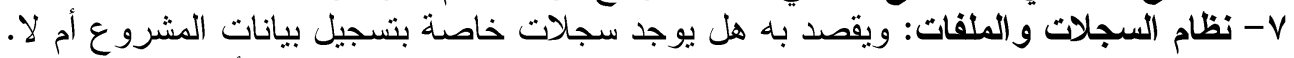

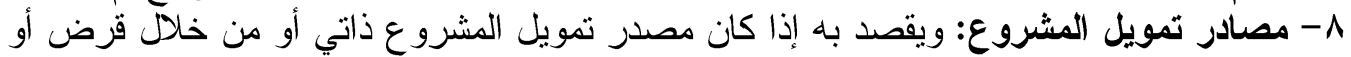
الأثنين معاً.

ب- دور الجمعيات الأهلية في تنمية المشروعات الصغيرة ومتناهية الصغر:

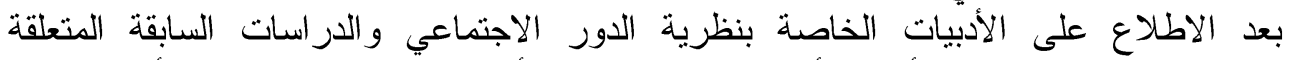

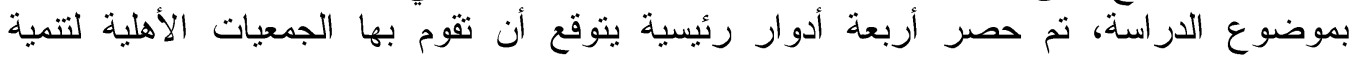

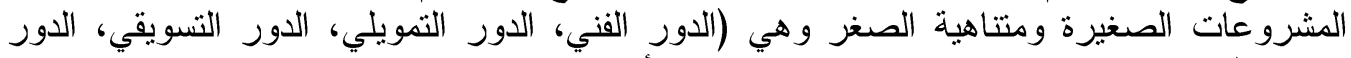

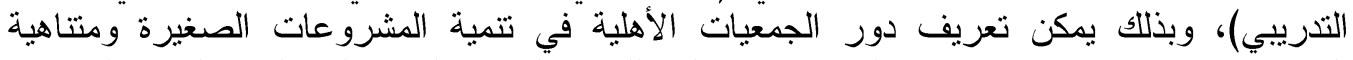

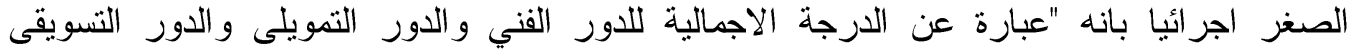

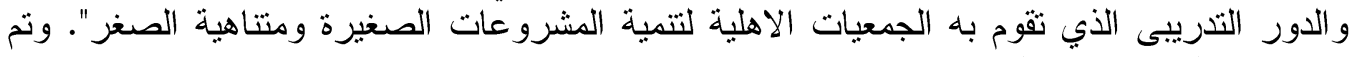

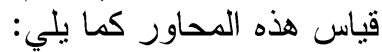
ا- الاور القني: ويقصدي به مجموعة الخدمات الفنية التي تقدمها الجمعيات الأهلية لأصحاب

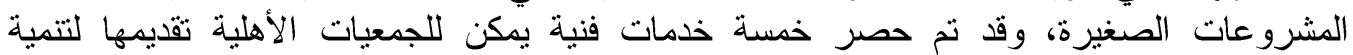

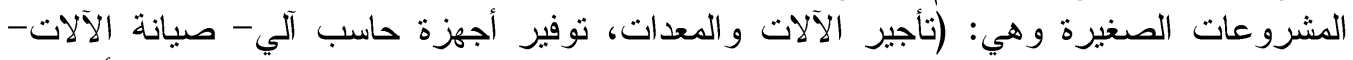

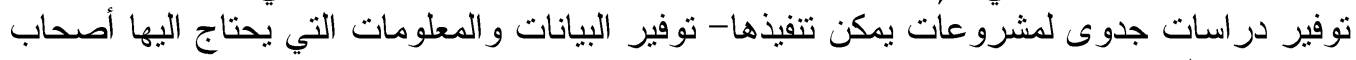

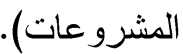
ץ- الاور التمويلي: ويقصد به مجموعة الخدمات التمويلية التي تقدمها الجمعيات الأهلية لأصحاب

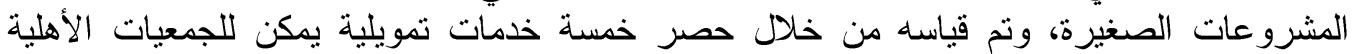

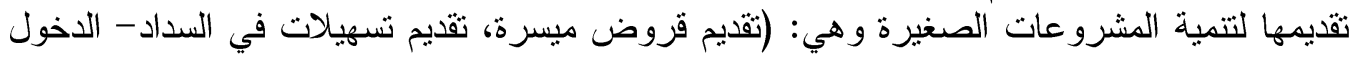

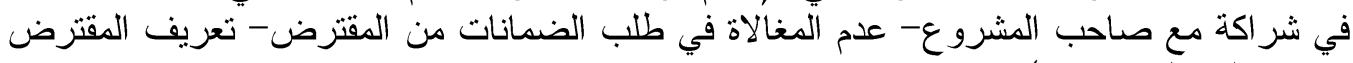

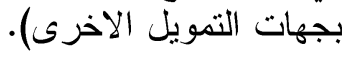
ب- الدور التسويقي: ويقصد باته مجموعة الخدمات التسويقية التي تقدمها الجمعيات الأهلية لأصحاب

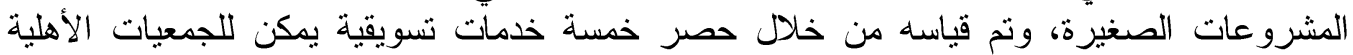

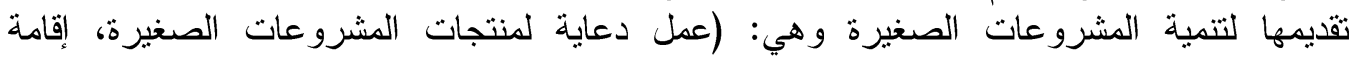

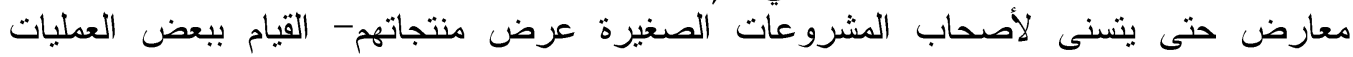
التسويقية متل النقل او التخزين- البحث عن فرص لتندين لتصدير منتجات المشروعات الصغيرةة- إقامة

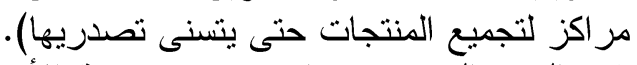

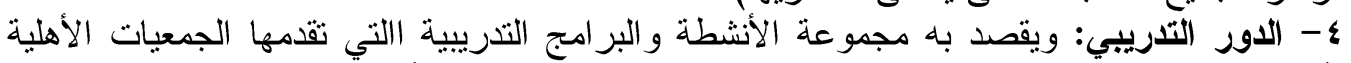

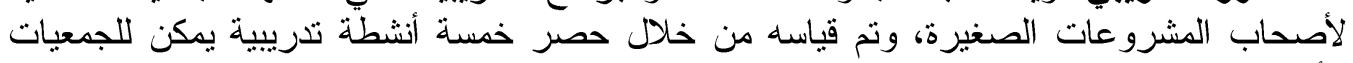

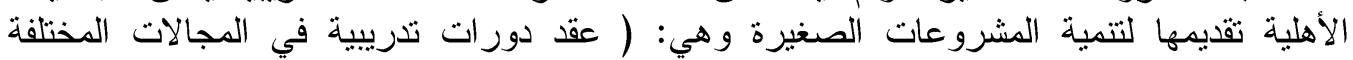

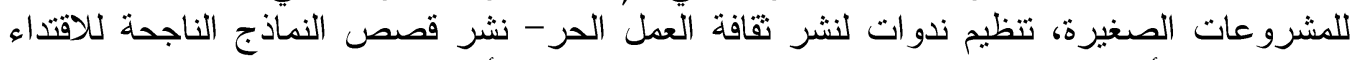

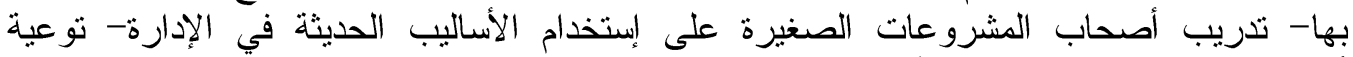
أصحاب المشروعات الصغيرة بأهمية المحافظة على الصئل البيئة).

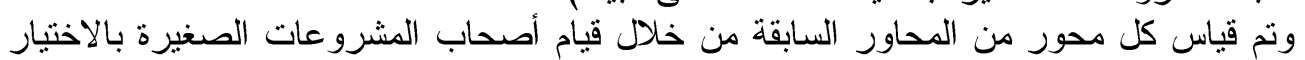

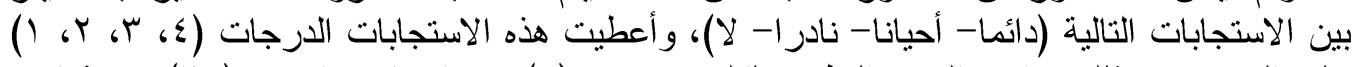

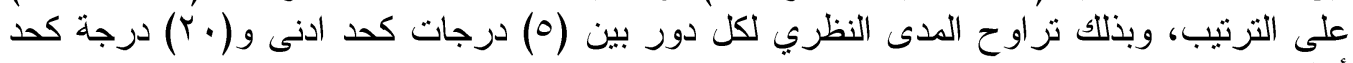

Fayoum J. Agric. Res. \& Dev., Vol. 33, No.2, July, 2019 
๑.

ه - الارجة الاجمالية لدور الجمعيات الأهلية في تنمية المشروعات الصغيرة ومتناهية الصغر:

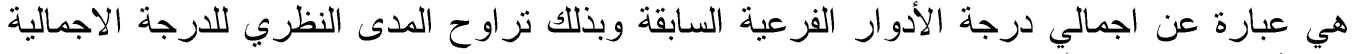

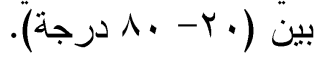

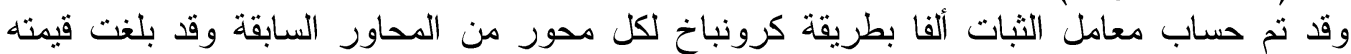

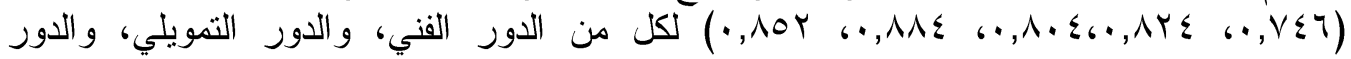

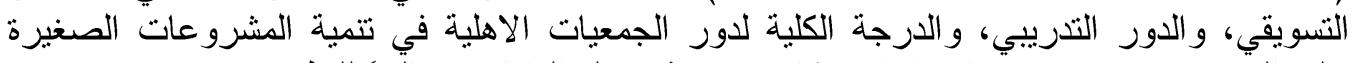

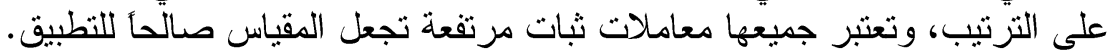
النتائج البحثية ومناقثتئها

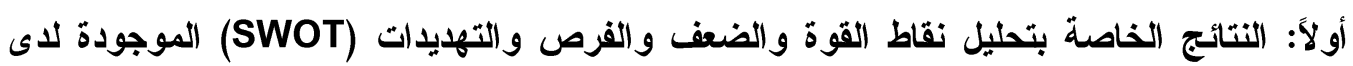

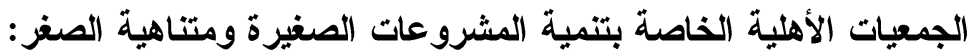

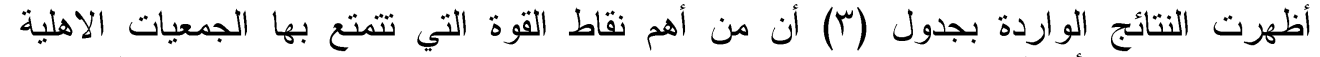

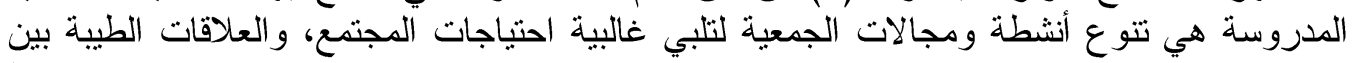

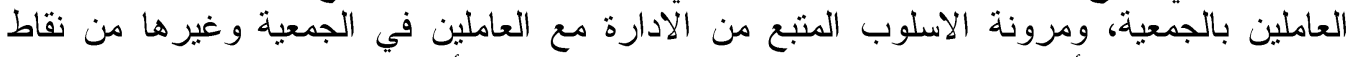

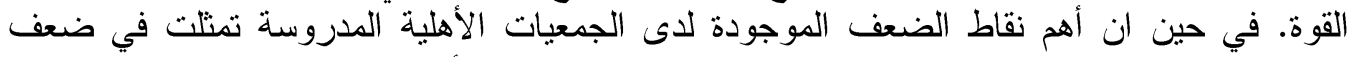

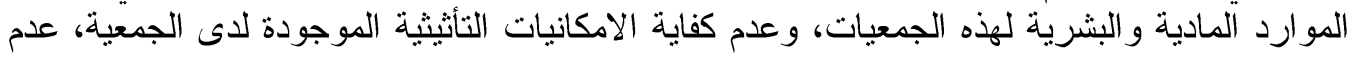

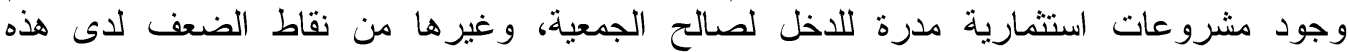
الجمعيات.

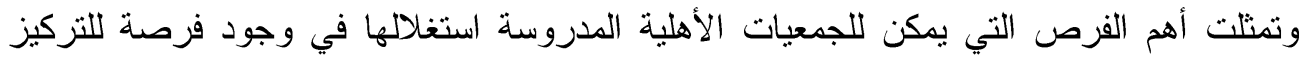

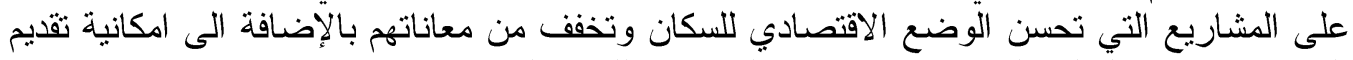

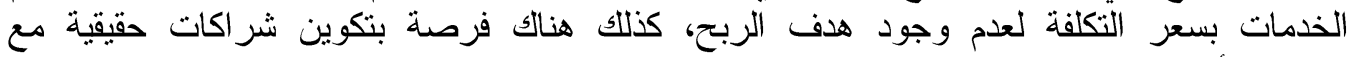

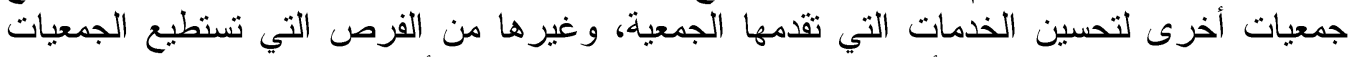

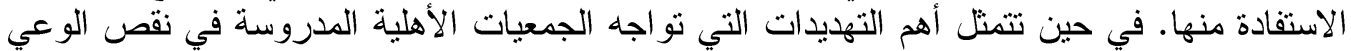

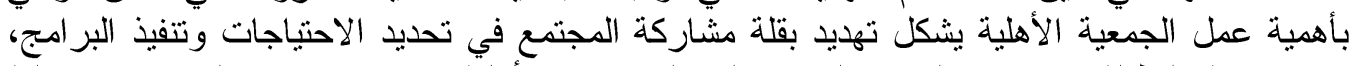

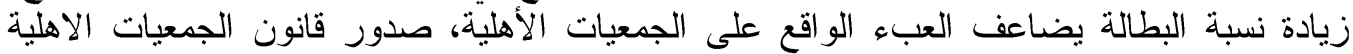

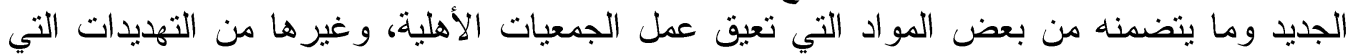
تعوق عمل الجمعيات الأهلية.

Fayoum J. Agric. Res. \& Dev., Vol. 33, No.2, July, 2019 
جدول (r) التحليل الرباعي (SWOT) للجمعيات الأهلية المدروسة

\begin{tabular}{|c|c|c|c|c|}
\hline \multicolumn{2}{|c|}{ تحليل البيئة الخارجية } & \multicolumn{3}{|c|}{ تحليل البيئة الاخلية } \\
\hline التهايدات & الفرص & نقاط الضعف & نقاط القوة & 5 \\
\hline 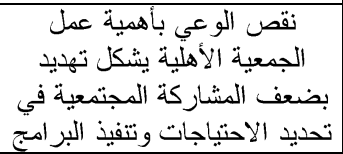 & 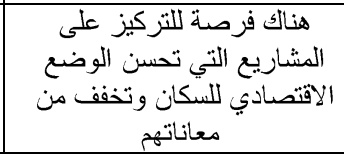 & و البشرية لهذه الجمعيات. & الجوع أنشطة لتلبي ومجاليةت & 1 \\
\hline 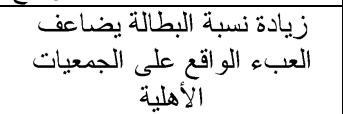 & تقديم الخدمات بسعر التكلفة لعدم & عدم كفاية الامكانيات التأثيثية & العاملين بالجمعية. الطيبة بين & r \\
\hline 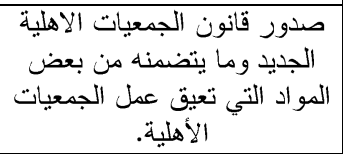 & 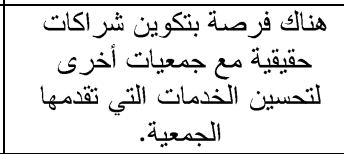 & 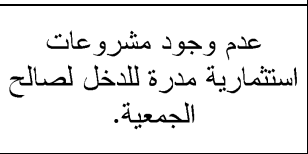 & من الادارة مع الاسلوب المتبع & $r$ \\
\hline زيادة معدل الفقز نتيجة للارتفاع الاسعار & 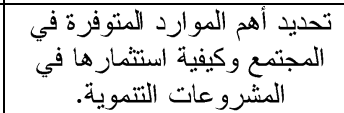 & قلى الكو العر البشرية المدربة الاداري. & 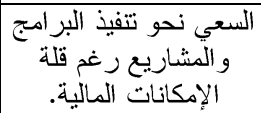 & $\varepsilon$ \\
\hline زيادة المنافسة بين الجمعيات فريل & 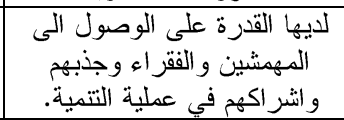 & 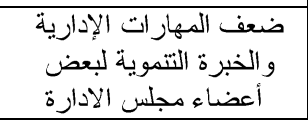 & 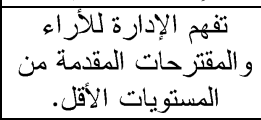 & 0 \\
\hline 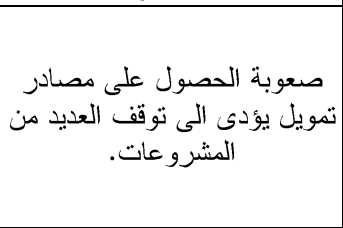 & 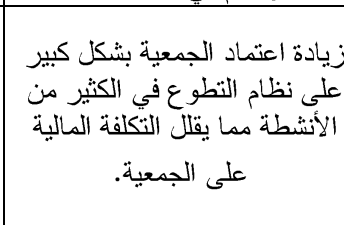 & ضعف الالتنز ام بحضور & 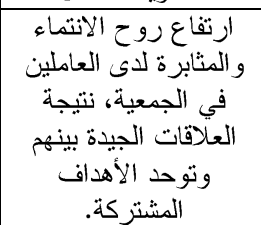 & 9 \\
\hline 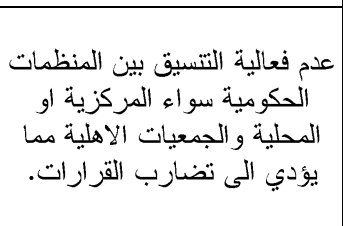 & الاستفادة من التكنولوجيا المتوفرة المبرة & 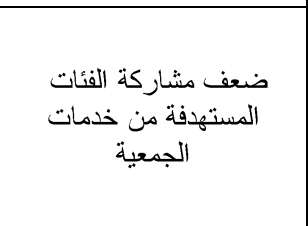 & 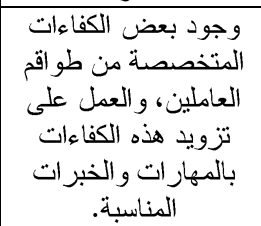 & $v$ \\
\hline 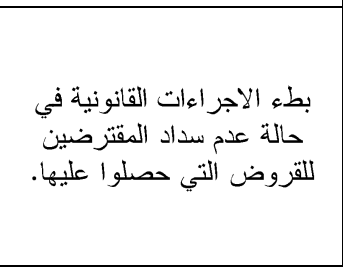 & 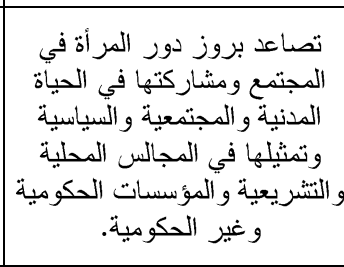 & ضشع تبادل المعلومات و & 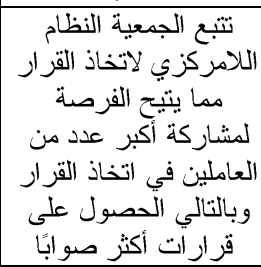 & $\wedge$ \\
\hline الناجحة فية استمر ار المشرو النتهاء التمويل & 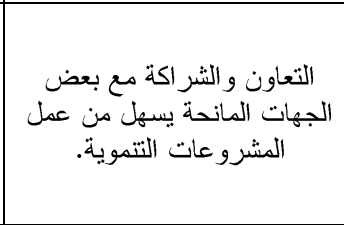 & 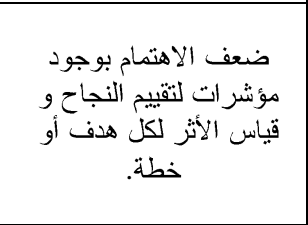 & 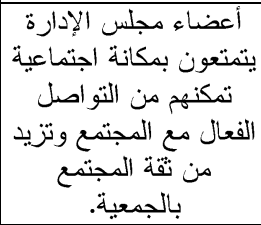 & 9 \\
\hline عدم وجود جهاز إداري خاصة & 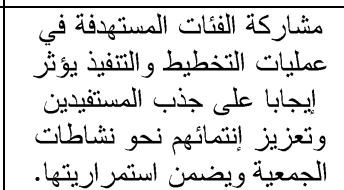 & 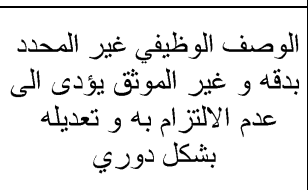 & و وظرود حصر بأعداد المشيدين & 1. \\
\hline
\end{tabular}

المصدر: بيانات الار اسة الميداتية.

Fayoum J. Agric. Res. \& Dev., Vol. 33, No.2, July, 2019 
or

ويمكن التوصل من نتائج هذا التحليل إلى أن الجمعيات الأهلية المدروسة لديها الكثير من نقاط

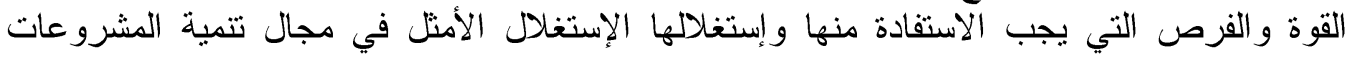

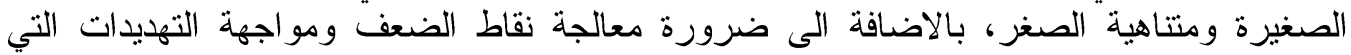
تعوق عمل هذه الجمعيات، اذا كان هناك رغبة حقيقية في النهوض بدورة هذور هذه الجمعيات في تتمية

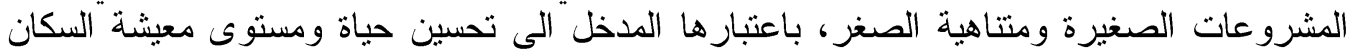

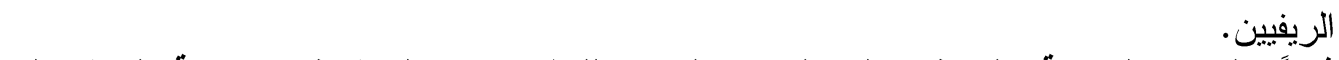
ثاتياً: النتائج الخاصة بالتعرف على الوضع الراهن الثن للمشروعات الصغيرة ومتناهية الصغز التي تخدمها الجمعيات الأهلية المدروسية: التعائة

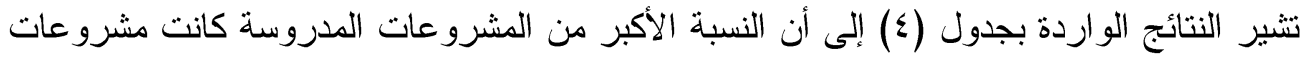

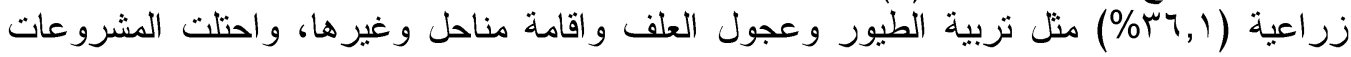

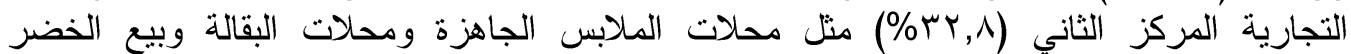

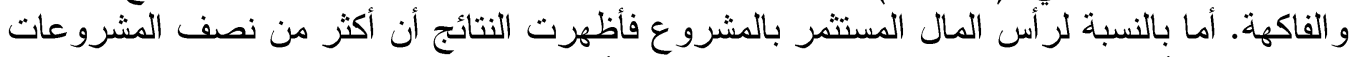

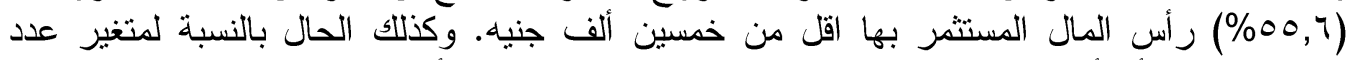

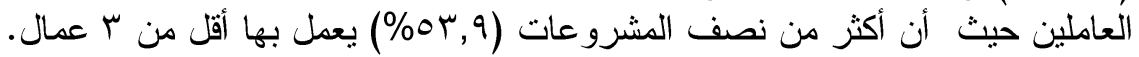

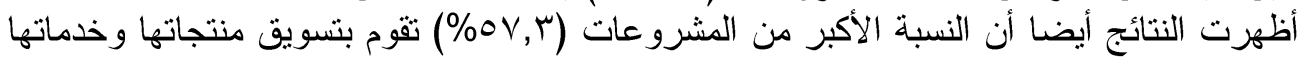

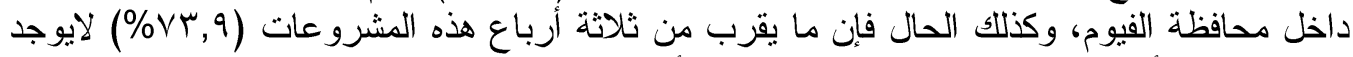

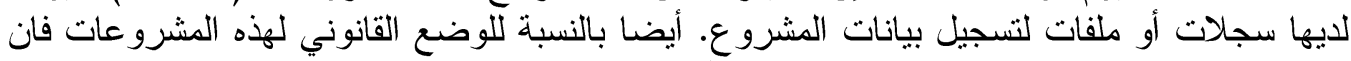

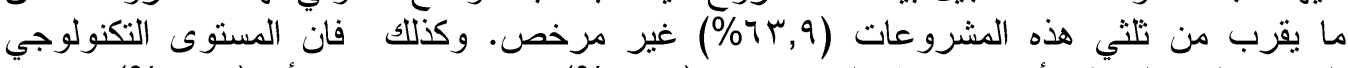

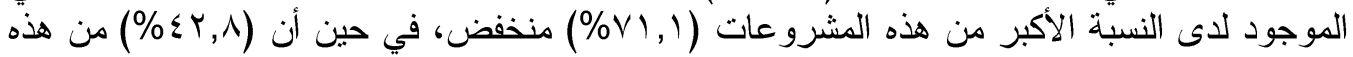

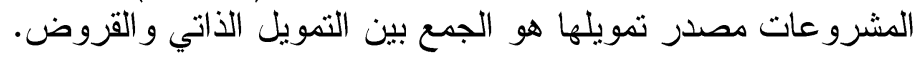

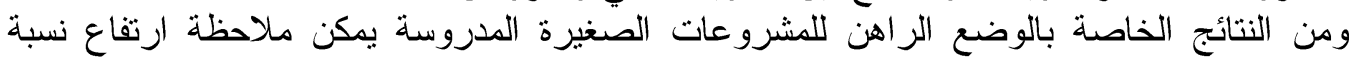

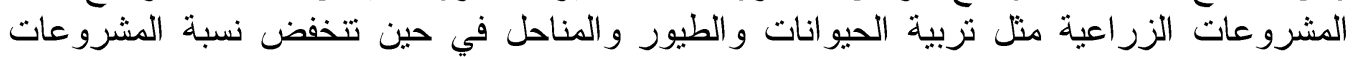
الصناعية، وذللك في الوقت الذي ينبغى على الجمعيات الأهلية أن تسعى لإحداث الثين التنسيق و التكامل

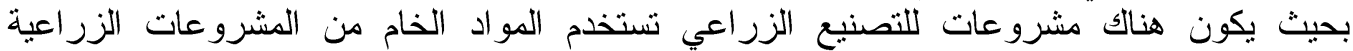

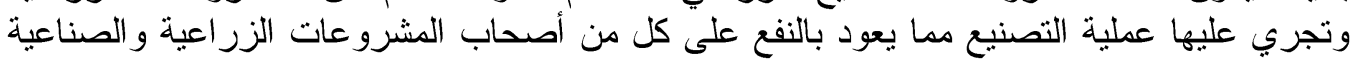
على حد سو اء. يلاحظ أيضا انخفاض نسبة تصدير منتجات المشروعات الصغيرة ومتتاهية الصغر الى الخارج، و هنا يأتي دور الجمعيات الاهلية في مساعدة اصحاب المشروعات في تصدير منتجاتهم من خلاله

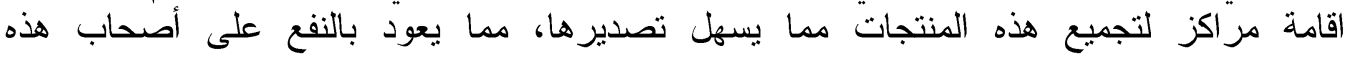
المشرو عات.

Fayoum J. Agric. Res. \& Dev., Vol. 33, No.2, July, 2019 
Or

جدول (؛) الوضع الراهن للمشروعات الصغيرة ومتناهية الصغر التي تخدما الجمعيات الأهلية

\begin{tabular}{|c|c|c|c|c|c|}
\hline$\%$ & التكر ار & المتغيرات & $\%$ & التكرار & المتغير ات \\
\hline 00,1 & $1 \ldots$ & ץ- رأس المال المستثمر بالمشروع: أقل من الفيه & $r, 1$ & 70 & ا- - نوع المشروع: \\
\hline$r 0,0$ & $7 \varepsilon$ & - من •0- . . ا الف جنيه & $11, \mathrm{~V}$ & YI & - صناعي \\
\hline \multirow[t]{2}{*}{$\wedge, 9$} & 17 & - أكثر من . . 1 الف جنيه & $r r, \Lambda$ & 89 & - تجاري \\
\hline & & & 19,8 & ro & - خدمي \\
\hline$\Delta V, r$ & $1 \cdot r$ & ـ - توزيع منتجات المشروع: & or, 9 & $9 \vee$ & 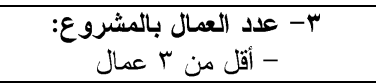 \\
\hline$r q, \varepsilon$ & VI & - بين المحافظات & $r \cdot, \cdot$ & $0 \leq$ & - من ب- 0 عمال \\
\hline$r, r$ & 7 & - تصدير للخارج & 17,1 & rq & - اكثز من 0 عمال \\
\hline 94,9 & 110 & 1- الوضع القانوني للمشروع: & Y., & $\leqslant V$ & •- نظام السجلات و الملفات: \\
\hline$r 4,1$ & 70 & - مرخص & $V^{2}, 9$ & Irr & - لا يوجد \\
\hline rq, & $\varepsilon V$ & ^- مصادر تمويل المشروع: & $v 1,1$ & $1+1$ & - المستوى التكنولوجي المستخدم: - منذف \\
\hline$r 1,1$ & 07 & - قرض & $Y \cdot, Y$ & $r v$ & - متوسط \\
\hline$\varepsilon Y, \wedge$ & $V V$ & - الأثثين معاً & $\Lambda, r$ & 10 & - مرتفع \\
\hline
\end{tabular}

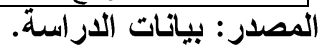

ثالثاً: النتائج الخاصة بوصف دور الجمعيات الأهلية في تنمية المشروعات الصغيرة ومتناهية الصغر

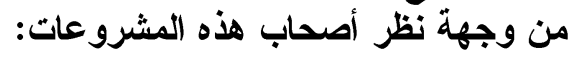
أظهرت النتائج الواردة بجدول (0) أن الدورات الدور الفني الذي تقوم به الجمعيات الأهلية لتنمية

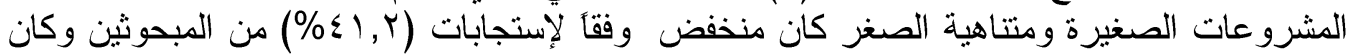

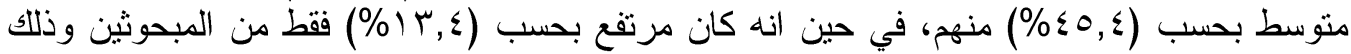

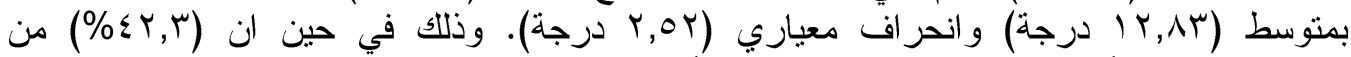

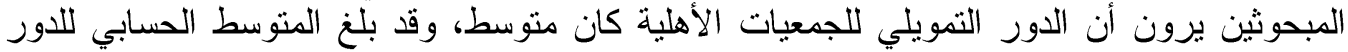

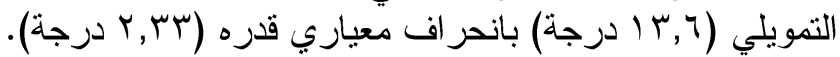

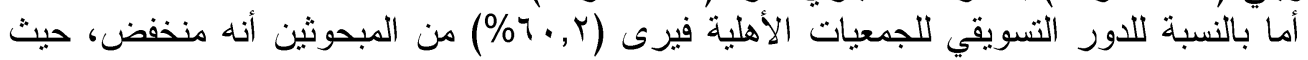

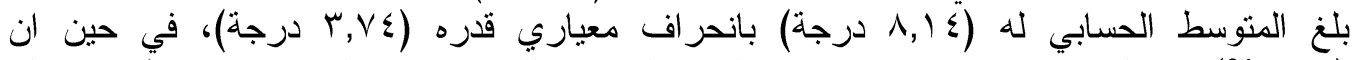

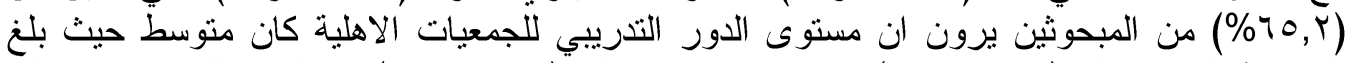

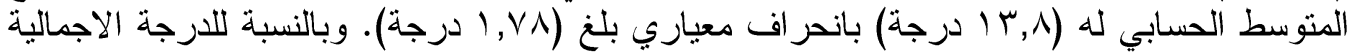

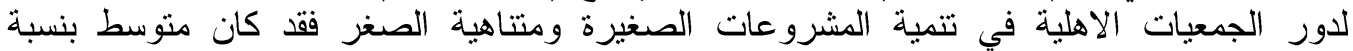

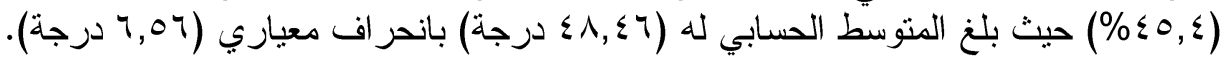

Fayoum J. Agric. Res. \& Dev., Vol. 33, No.2, July, 2019 
جدول (0) دور الجمعيات الأهلية في تنمية المشروعات الصغيرة ومتناهية الصغر

\begin{tabular}{|c|c|c|c|c|}
\hline الانحر اف المعياري & المتوسط الحسابي & $\%$ & التكرار & دور الجمعيات الاهلية في تنمية المشروعات \\
\hline \multirow[t]{3}{*}{ r,Or } & $\mid r, \Lambda r$ & $\varepsilon 1, r$ & $V \varepsilon$ & - - منخفض (ألّل من الفني: درجات) \\
\hline & & $£ 0, \S$ & NT & - متوسط (11- 10 درجة) \\
\hline & & $1 \%, \varepsilon$ & $r \varepsilon$ & - مرتفع (َ ا درجة فأكثر) \\
\hline \multirow[t]{3}{*}{ r, r } & $1 \pi, 4$ & $r_{0,1}$ & Tr & - منخفض (أقل من التمويلي: الدرجات) \\
\hline & & $\varepsilon r, r$ & 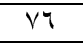 & - متوسط (11- 10 درجة) \\
\hline & & $Y Y, Y$ & $\varepsilon 1$ & - مرتفع ( (1 درجة فأكثر) \\
\hline \multirow[t]{3}{*}{$r, v \varepsilon$} & $\Lambda, 1 \leq$ & $7 \cdot, r$ & 1.9 & - منخفض (أقلّ من التسويقي: درجات) \\
\hline & & $r \wedge, 9$ & or & - متوسط (11- 10 درجة) \\
\hline & & $9, r$ & 11 & - مرتفع ( آ درجة فأكثر) \\
\hline \multirow[t]{3}{*}{$1, \vee \wedge$} & $1 \mu, \Lambda$ & $r_{1,0}$ & rq & - ـ - منخفض (ألقل من التدريبي: \\
\hline & & $70, r$ & $11 \mathrm{~V}$ & - متوسط (11- 10 درجة) \\
\hline & & $1 r, r$ & $r \leqslant$ & - مرتفع (4 ا درجة فأكثر) \\
\hline \multirow[t]{3}{*}{7,07} & $\left.\sum \wedge, \leq\right\rceil$ & $r 9,0$ & v) & - الدخفة الكلية لاور الجمعياتة: \\
\hline & & $\varepsilon 0, \varepsilon$ & $\Lambda T$ & - متوسط (اء- . آ درجة) \\
\hline & & 10,1 & TV & - مرتفعة (آ درجة فأكثر) \\
\hline
\end{tabular}

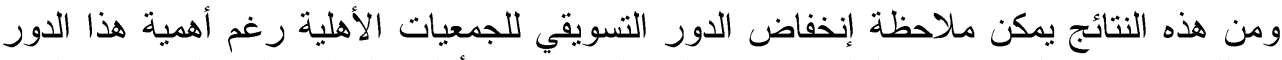

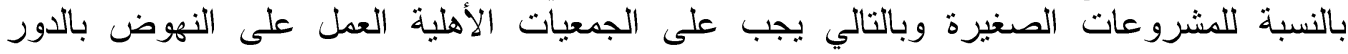

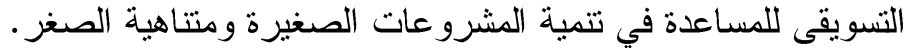

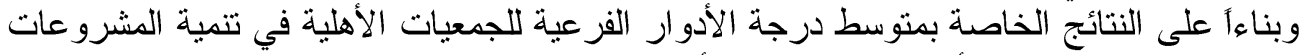

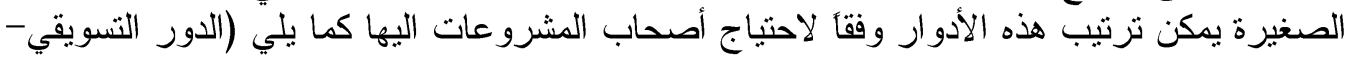

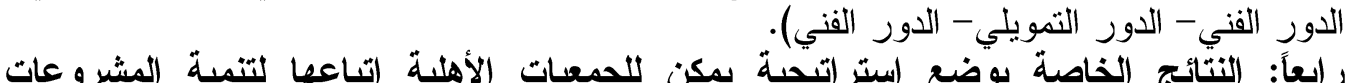
الصغيرة ومتتاهية الصغز الصغة

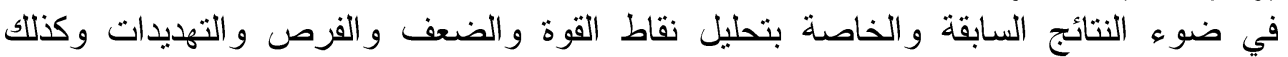

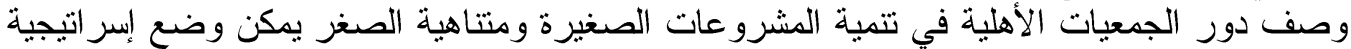

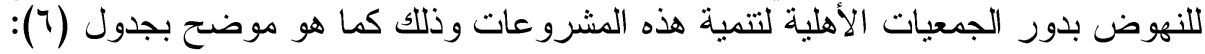

Fayoum J. Agric. Res. \& Dev., Vol. 33, No.2, July, 2019 


\section{๑०}

جدول (ا) استراتيجية مقترحة للنهوض بدور الجمعيات الأهلية في تنمية المشروعات الصغيرة

ومتناهية الصغز

\begin{tabular}{|c|c|c|c|c|}
\hline الاور التدريبي & الاور (لقني & الاور التسويقي & الاور التمويلي & \\
\hline 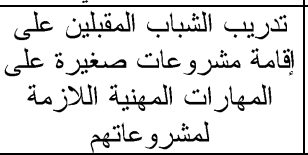 & 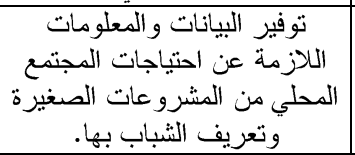 & 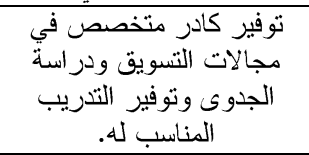 & 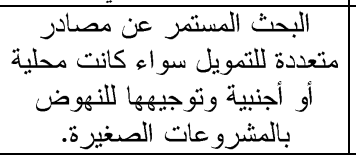 & -1 \\
\hline 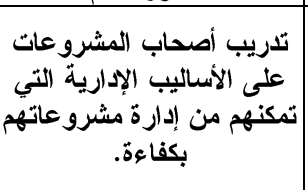 & 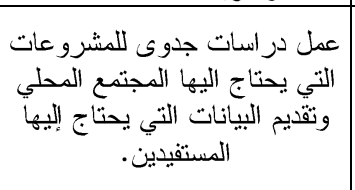 & أنعزيف أصحاب المشرة بالأسو التي يجات & 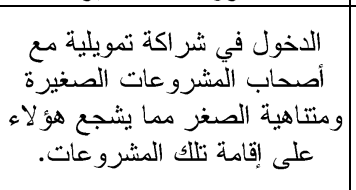 & $-Y$ \\
\hline تدريب أصحاب المشروعات التهار التشيقة & 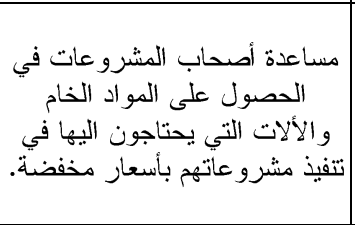 & 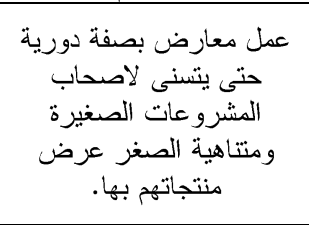 & 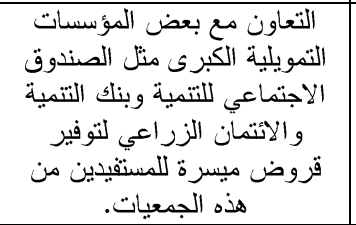 & r \\
\hline 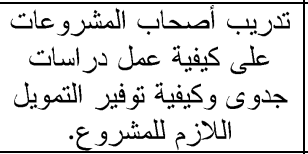 & 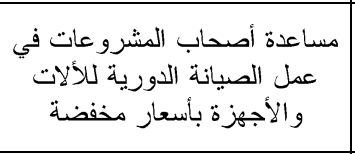 & 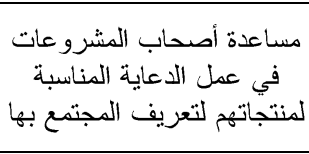 & 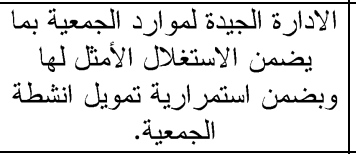 & $-\varepsilon$ \\
\hline 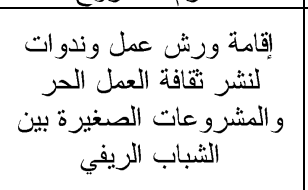 & 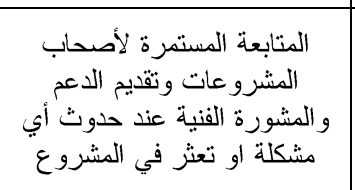 & 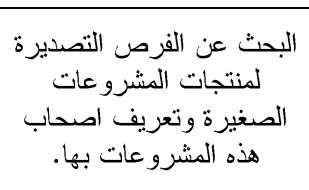 & 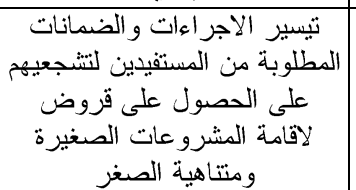 & -0 \\
\hline
\end{tabular}

المر اجع باللغة العربية

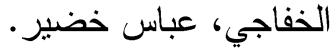

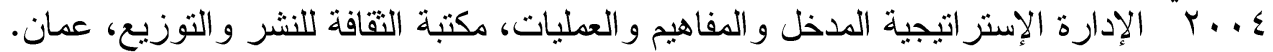

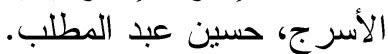

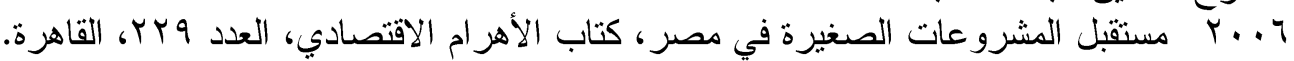

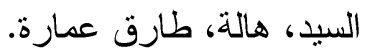

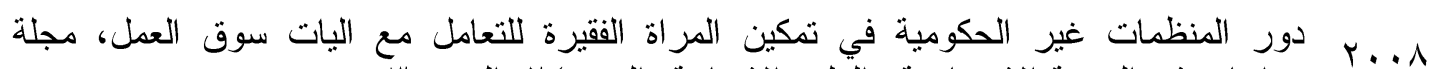

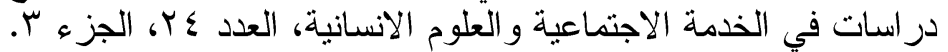

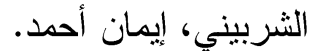

فاعلية النظم الخبيرة في رفع كفاءة أداء الجمعيات الأهلية في جمهورية مصر العربية، معهد التخطيط القومي، القاهرة. r... المركز المصري لدراسات السياسات العامة العاهرة r.lV دور مؤسسات المجتمع المدني في التتمية الاقتصادية

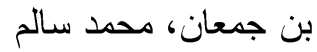

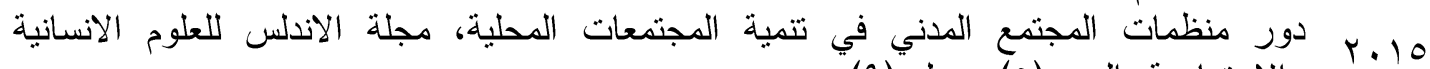
و الاجتماعية، العدد (0)، مجلد (9).

Fayoum J. Agric. Res. \& Dev., Vol. 33, No.2, July, 2019 


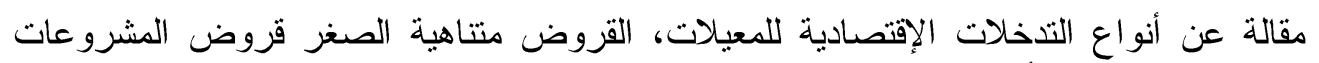

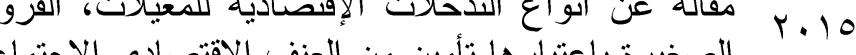
الصغيرة باعتبار ها تأمين من العنف الاقتصادي الاجتماعي، مؤسسة الفنار . لألفات

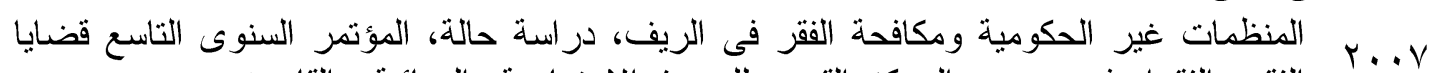

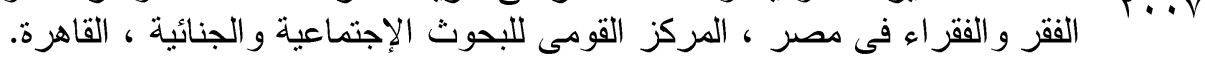

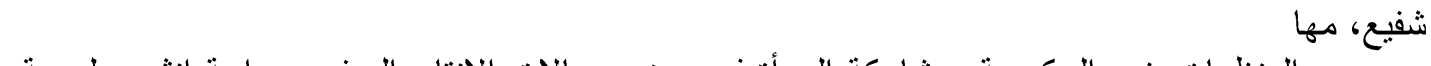

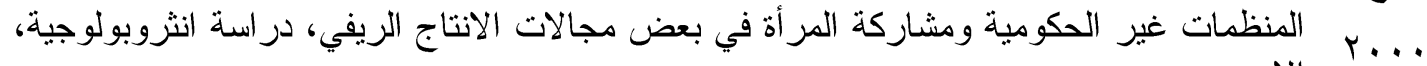

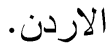

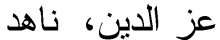
. . . . . بالأمتمع المدنى، موسوعة الثباب السياسية، العدد(ه)، مركز الدراسات السياسية والاستراتيجية

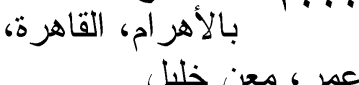
عمر ، معن خليل (1991 19 نقد الفكر الاجتماعي المعاصر ، دار الافاق الجديدة، بيروت. غيث، محمد عاطف 199V أماموس علم الاجتماع، دار المعرفة الجامعية، الاسكندرية.

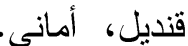

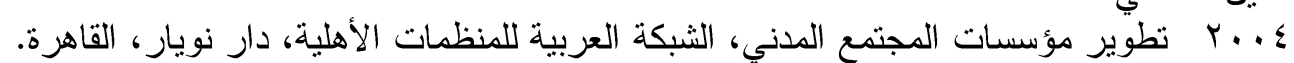

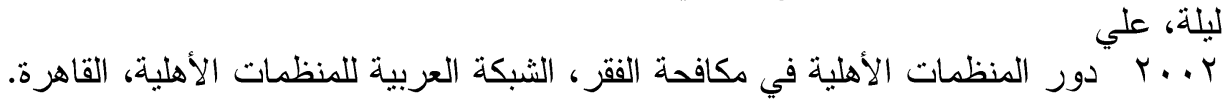
محمود، احمد جمال محمد المنظ دور المنظمات الريفية الاهلية في التتمية الريفية ومقتضايات تطوير ها بمحافظة الثرقية، المؤتمر العلمي الثالث، كلية التجارة، جامعة الزقازيق.

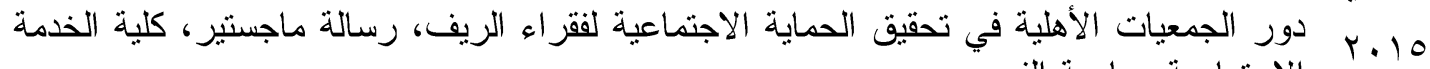

Clark, J.,

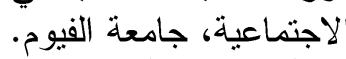
المر اجع باللغة الاتجليزية

1991 Democratizing Development: the role of Voluntary Organization, Earth scan, London,

Stephenson G., Lev L., and Brewer L.

2007

Understanding the Link Between Farmers' Market Size and Management Organization. Special Report, No. 1082-E, Oregon State University.

Fayoum J. Agric. Res. \& Dev., Vol. 33, No.2, July, 2019 
- V

\title{
THE ROLE OF NGOS IN THE DEVELOPMENT OF MICRO AND SMALL ENTERPRISES IN RURAL AREAS IN FAYOUM GOVERNORATE
}

\author{
Safaa Ragaey Abdel Nabby El Saied \\ Agricultural Economics Dept, Fac Of Agric, El Fayoum Univ.
}

\begin{abstract}
This study aimed basically to identify the role of NGOs in the development of micro and small enterprises in rural Fayoum governorate, through the following sub-objectives: SWOT analysis of NGOs in the development of micro and small enterprises, describe the role of NGOs for development the small and micro enterprises in their various fields (technical, finance, marketing, training) from the point of view of the owners of these enterprises. found a strategy that NGOs can follow to develop small and micro enterprises. The data were collected from 36 a NGOs' in Fayoum and Etsa districts in Fayoum governorate using a guide to interview with the directors of these associations to identify the strengths, weaknesses, opportunities and threats of these associations. Data on the role of NGOs in the development of micro and small enterprises were collected from 180 of the owners of these enterprises. Using a personal interview questionnaire. Frequency distribution tables, percentages, mean arithmetic, standard deviation, and alpha $(\alpha)$ were used in the Cronbach method.

The most important results were the SWOT analysis of the strengths, weaknesses, opportunities and threats of the studied NGOs. The results also showed that the technical role played by NGOs for the development of small and micro enterprises is average (45.4\%), $42.3 \%$ of the respondents believe that the funding role of NGOs was average. As for the marketing role of NGOs, $60.2 \%$ of the respondents said that it was low, while $65.2 \%$ For NGOs was average for the overall score of NGOs' role in project development (45.4\%). The study found a strategy that NGOs can follow to develop small and micro enterprises as the best solution to promote rural communities and improve rural living standards.
\end{abstract}

Fayoum J. Agric. Res. \& Dev., Vol. 33, No.2, July, 2019 